\title{
The Effect of Latent Heat Release on the Evolution of a Warm Occluded Thermal Structure
}

\author{
DEREK J. POSSELT \\ Cooperative Institute for Meteorological Satellite Studies, Space Science and Engineering Center, University of Wisconsin-Madison, \\ Madison, Wisconsin \\ JONATHAN E. MARTIN \\ Department of Atmospheric and Oceanic Sciences, University of Wisconsin-Madison, Madison, Wisconsin
}

(Manuscript received 23 January 2003, in final form 28 July 2003)

ABSTRACT

The effect of latent heat release on the development of the occluded thermal structure in a major winter storm is examined through comparison of full physics (FP) and no-latent-heat-release (NLHR) simulations of the event performed using the fifth-generation Pennsylvania State University-NCAR Mesoscale Model (MM5). Though both simulations possess a well-developed occluded thermal ridge near the surface, the 3D structure of their respective occluded quadrants is quite different. In particular, the FP simulation depicts the canonical, tropospheredeep warm occluded thermal structure, whereas the NLHR simulation produces only a shallow, poorly developed one. Consistent with these differences in tropospheric thermal structure, the FP cyclone displays a robust treble clef potential vorticity (PV) distribution in the upper troposphere in its postmature phase, while a considerably less robust version characterizes the NLHR simulation. The PV minimum of the treble clef overlies a poleward sloping column of warm, weakly stratified air that extends through the depth of the troposphere and is a signature of the trowal, the essential structural feature of warm occluded cyclones. Consequently, examination of the role played by latent heat release in production of the occluded thermal structure in this case is made through consideration of its influence on the evolution of the upper-tropospheric PV morphology.

It is found that direct dilution of upper-tropospheric PV by midtropospheric latent heat release initiates formation of a local, upper-tropospheric PV minimum, or low PV tongue, to the northwest of the surface cyclone center. The production of this PV minimum initiates a cutting off of the upper-tropospheric PV anomaly associated with the surface development. The upper-tropospheric circulation associated with this cutoff anomaly, in turn, forces the advection of low $(<1 \mathrm{PVU})$ values of PV into the developing PV trough. This combination of kinematic and diabatic processes acts to produce both the tropopause PV treble clef as well as the underlying warm occluded thermal structure in the FP simulation. In contrast, though an adiabatic kinematic tendency for production of a treble clef PV morphology operates in the NLHR simulation, the resulting PV and thermal structures are weaker and slower to evolve than those produced in the FP simulation. Thus, it is suggested that latent heat release plays an indispensable role in the production of the characteristic occluded thermal structures observed in nature.

\section{Introduction}

As first described by Bjerknes and Solberg (1922), the midlatitude cyclone undergoes significant structural modification as it approaches its postmature phase. Included among the changes that characterize this socalled occluded stage of the life cycle are the adoption of an increasingly equivalent barotropic structure in the vertical as well as the development of a lower tropospheric thermal ridge connecting the sea level pressure (SLP) minimum to the peak of the warm sector. Ac-

Corresponding author address: Dr. Jonathan E. Martin, Dept. of Atmospheric and Oceanic Sciences, University of Wisconsin-Madison, 1225 W. Dayton St., Madison, WI 53706.

E-mail: jon@meteor.wisc.edu cording to the classical model, the midtropospheric air lying above the near-surface position of this thermal ridge was thought to have originated in the surface warm sector and been forced to ascend by the intersection of the cold and warm fronts at the commencement of a process referred to as occlusion. The vertical structure that was presumed to result from this sequence of events consists of an axis of maximum $\theta\left(\theta_{e}, \theta_{\mathrm{es}}\right)$ (in both horizontal and vertical cross sections) embedded within a region of reduced static stability between two significant baroclinic zones, as depicted in Fig. 1. Though considerable debate has raged regarding the mechanisms that might operate to produce it, there is little disagreement that such a structure represents the canonical thermal structure of a warm occluded cyclone.

A refined 3D description of the warm occluded ther- 

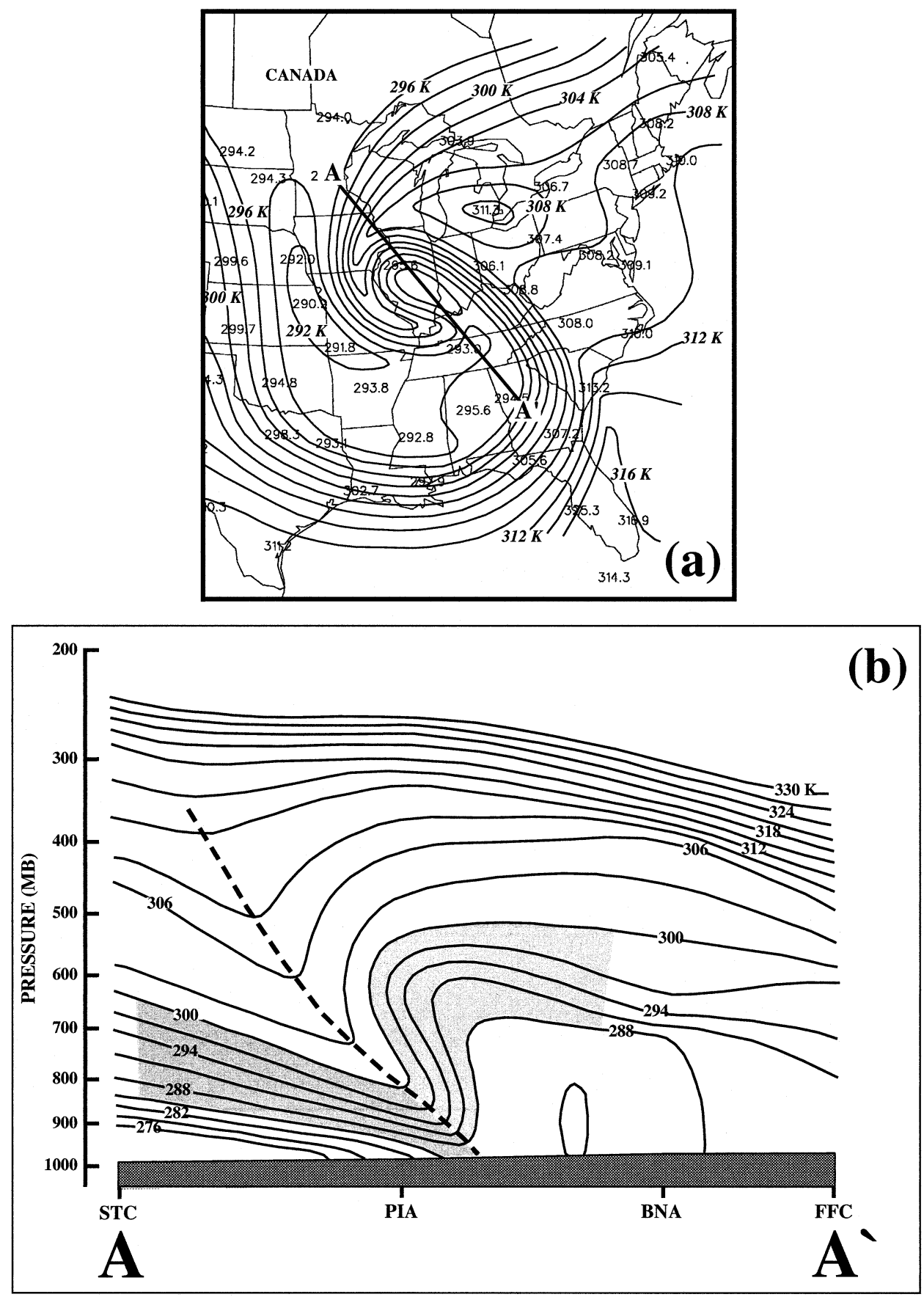

FIG. 1. (a) The 700-hPa equivalent potential temperature $\left(\theta_{e}\right)$ at 0000 UTC $20 \mathrm{Jan} 1995$, with $\theta_{e}(\mathrm{~K})$ contoured every $2 \mathrm{~K}$. Cross-section along line $\mathrm{A}-\mathrm{A}^{\prime}$ is shown in Fig. 1b. (b) Vertical cross section of equivalent potential temperature $\left(\theta_{e}\right)$ along line $\mathrm{A}-\mathrm{A}^{\prime}$ in (a) [from St. Cloud, MN (STC), to Peoria, IL (PIA), to Nashville, TN (BNA), to Peachtree City, GA (FFC)] at 0000 UTC 20 Jan 1995. Solid lines are moist isentropes $(\mathrm{K})$ and are contoured every $3 \mathrm{~K}$. Dashed line indicates the canonical axis of max $\theta_{e}$ that slopes upward and poleward in a warm occlusion. Light (dark) shading represents the cold (warm) frontal baroclinic zone involved in this occluded structure. Adapted from Martin (1998a).

mal structure presented by Bjerknes and Solberg (1922) was developed more than 50 years ago by scientists at the Canadian Meteorological Service (Crocker at al. 1947; Godson 1951; Penner 1955; Galloway 1958,
1960). These studies noted the ubiquity of a westward slope to the crests of the thermal wave at successive heights in occluded cyclones. Penner (1955) referred to this "sloping valley of tropical air," as it had been pre- 
viously described by Godson (1951), as the trowal (trough of warm air aloft). The observation that the cloudiness and precipitation characteristic of the occluded quadrant of cyclones bore a closer correspondence to the trowal position than to the often weak surface warm occluded front led the Canadians to regard the trowal as the essential structural feature of a warm occluded cyclone. Present day computer animation technology along with high-resolution modeling capabilities have demonstrated the utility of the trowal conceptual model both in diagnosis and forecasting (e.g., Martin 1998a,b; Market and Cissell 2002).

Recent work has also shed light on the adiabatic dynamical processes that operate in the occluded quadrant. Martin (1999a) showed that the convergence of the along-isentrope component of the $\mathbf{Q}$ vector simultaneously accounts for quasigeostrophic (QG) forcing for ascent in the occluded quadrant while promoting the development of the characteristic occluded thermal ridge. Further refinement of that picture was offered by Martin (1999b), who discussed the distinct roles of geostrophic vorticity and deformation in the dynamics of the occluded quadrant. The nonfrontogenetic geostrophic deformation was found to be the central physical mechanism by which both the occluded thermal ridge and forcing for ascent within it were produced. Consistent with forced ascent in a nearly saturated environment, the developing occluded thermal ridge is often associated with significant latent heat release. Absent, thus far, in this emerging view of the dynamics of the occlusion process is any description of the role that this latent heat release might play in the evolution of the occluded thermal structure.

In a recent study of the evolution of a warm occlusion, Martin (1998a) noted that some occluded cyclones adopt a characteristic upper-tropospheric potential vorticity (PV) distribution (what he termed the "treble clef"). The treble clef PV distribution is characterized by an isolated, low-latitude high-PV feature that is connected to a high-latitude reservoir of high PV by a thin filament of high PV (Fig. 2a). Hoskins et al. (1985) demonstrated that, in an atmosphere in approximate thermal (gradient) wind balance, regions of high PV near the tropopause sit atop relatively cold columns of air, while relative minima of PV near the tropopause sit atop relatively warm columns of air. Thus, the characteristic tropospheric thermodynamic structure associated with the horizontal juxtaposition of two upper-level PV anomalies of unequal magnitude, separated by a relative minimum in PV (such as along line $\mathrm{A}-\mathrm{A}^{\prime}$ in Fig. 2a) precisely depicts the canonical warm occluded thermal structure (Fig. 2b). Martin (1998a) used this argument to conclude that the presence of an upper-tropospheric treble clef PV signature serves as a sufficient condition for asserting the presence of a warm occluded thermal structure in the underlying troposphere.

In classical terms, the sloping warm column beneath the upper-tropospheric PV minimum in Fig. 2b repre- sents warm-sector boundary layer air that has been lifted during the process of occlusion. In three dimensions, the warm axis identifies the position of the trowal, which tends to be a focus for precipitation production in occluded cyclones (Martin 1998a, 1999a). Consequently, the clouds and precipitation in the occluded quadrant of a cyclone are often nearly coincident with an uppertropospheric PV minimum. The strong connection between the morphology of the upper-tropospheric PV and the underlying occluded thermal structure, coupled with the constraint of PV conservation, provides a convenient framework within which to investigate the influence of latent heat release (LHR) on the formation of an occluded thermal structure.

In this paper we examine the role played by latent heat release in the evolution of the occluded thermal structure in a particularly intense midlatitude cyclone that affected southern New England on 1-2 April 1997. ${ }^{1}$ The analysis compares output from successful full physics (FP) and no-latent-heat-release (NLHR) numerical simulations of the storm obtained using the fifth-generation Pennsylvania State University-National Center for Atmospheric Research (PSU-NCAR) Mesoscale Model (MM5), version 3.5. An additional component of the analysis will involve piecewise PV inversion of the full physics model output in order to diagnose the influence of the flow associated with the diabatically generated PV on the upper-tropospheric PV distribution. The paper is organized as follows: Section 2 provides a model description as well as a limited assessment of the model simulation. Detailed analysis of the differences in tropospheric and tropopause thermal structure between the NLHR and FP simulations is presented in section 3. An examination of the manner in which these differences are related to LHR is undertaken in section 4. A discussion of the results is given in section 5, followed by conclusions and suggestions for future work in section 6 .

\section{Model description and evaluation}

\section{a. Model description}

The MM5 is a nonhydrostatic mesoscale numerical model that integrates the full nonlinear primitive equations. Prognostic variables carried in MM5 include perturbation pressure, temperature, water vapor mixing ratio, three-dimensional winds, and mixing ratios of a variety of microphysical quantities. Arakawa-Lamb B staggering of velocity variables with respect to scalars facilitates computation of horizontal advection and cen-

\footnotetext{
${ }^{1}$ In the course of this research, the role of LHR in the development of the occluded thermal structures in two other cyclones was investigated in detail. Based upon those analyses, we contend that the April 1997 event is a representative, though unusually robust, example of what appears to be a fundamental physical process. It is precisely because of its intensity that it serves as the most illustrative case.
} 

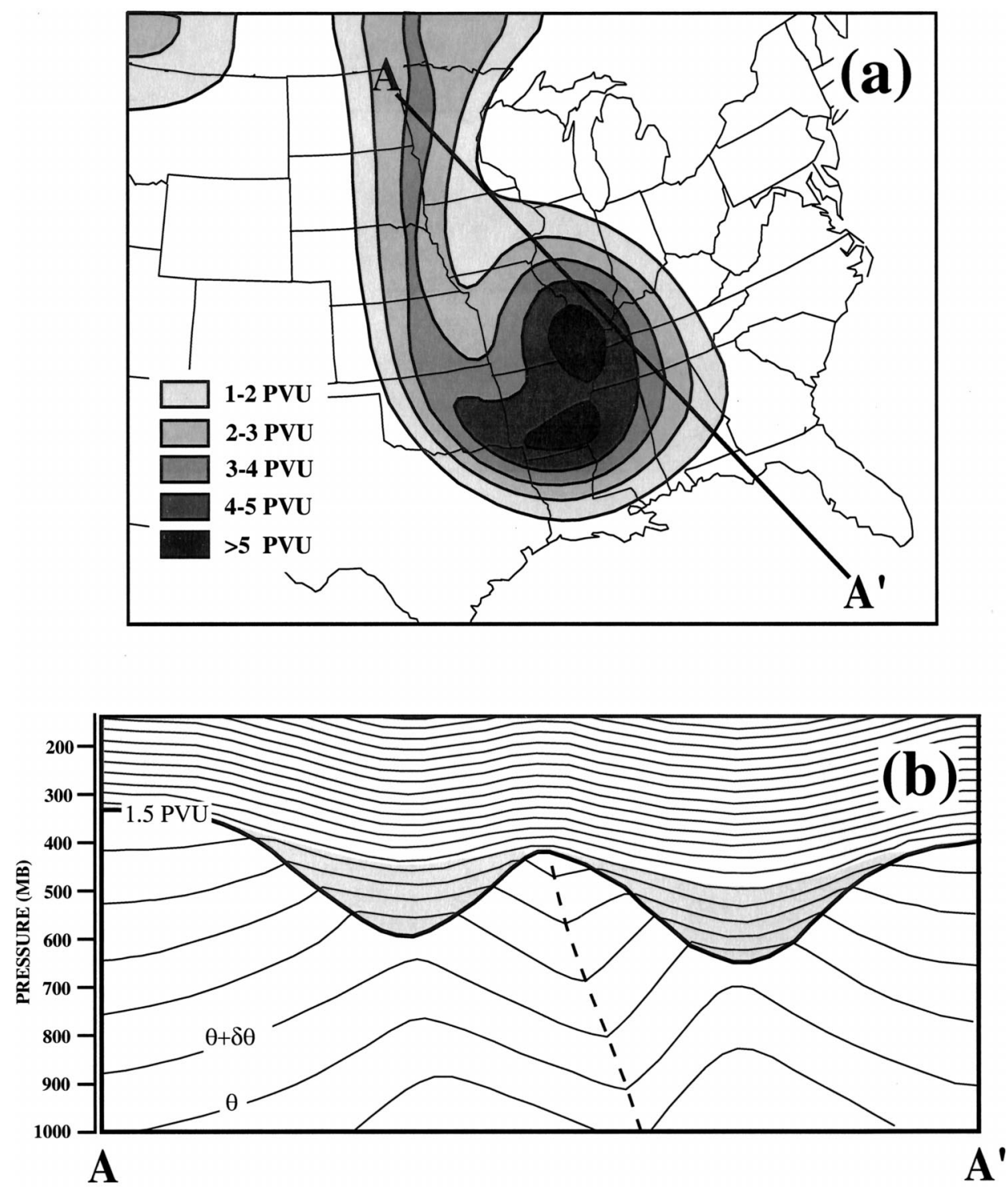

FIG. 2. (a) Schematic of treble-clef-shaped upper-tropospheric PV structure described in the text. Solid lines are isertels contoured and shaded in PVU (1 PVU $\left.=10^{-6} \mathrm{~m}^{2} \mathrm{~K} \mathrm{~kg}^{-1} \mathrm{~s}^{-1}\right)$. (b) Schematic cross section along $\mathrm{A}-\mathrm{A}^{\prime}$ of potential temperature $(\theta)$ in the vicinity of a treble-clef-shaped upper-tropospheric $\mathrm{PV}$ signature. The dashed axis denotes the sloping axis of warm air in the troposphere characteristic of an occluded cyclone. Adapted from Martin (1998a).

tered finite differences. Three-dimensional analyses of the atmospheric state are interpolated from a latitudelongitude mesh to a moveable limited-area domain on a Lambert conformal projection. A variable resolution 24-category topography and land-use dataset is used to determine albedo, roughness length, longwave emissivity, heat capacity, and moisture availability at the land surface. The model domain, depicted in Fig. 3, consists of two nested grids - a relatively coarse outer domain and a higher-resolution inner domain, with grid spacings of 60 and $20 \mathrm{~km}$, respectively. Thirty-seven terrain-following vertical sigma- $p$ layers, which gradually increase in vertical resolution from $40 \mathrm{hPa}$ above the boundary layer to approximately $5 \mathrm{hPa}$ near the surface, are used. The model top was located at $50 \mathrm{hPa}$.

Specific physical parameterizations include the Medium-Range Forecast (MRF) boundary layer scheme (Hong and Pan 1996) and a mixed-phase cloud microphysical package (Reisner et al. 1998). Subgrid-scale effects of cloud and precipitation are parameterized in the Grell (1993) cumulus scheme, while a combination of a modified version of the Rapid Radiative Transfer Model (RRTM) longwave (Mlawer et al. 1997) and Dudhia (1989) shortwave radiation schemes account for interaction between terrestrial and solar radiation and grid-scale cloud and clear air. A complete description 


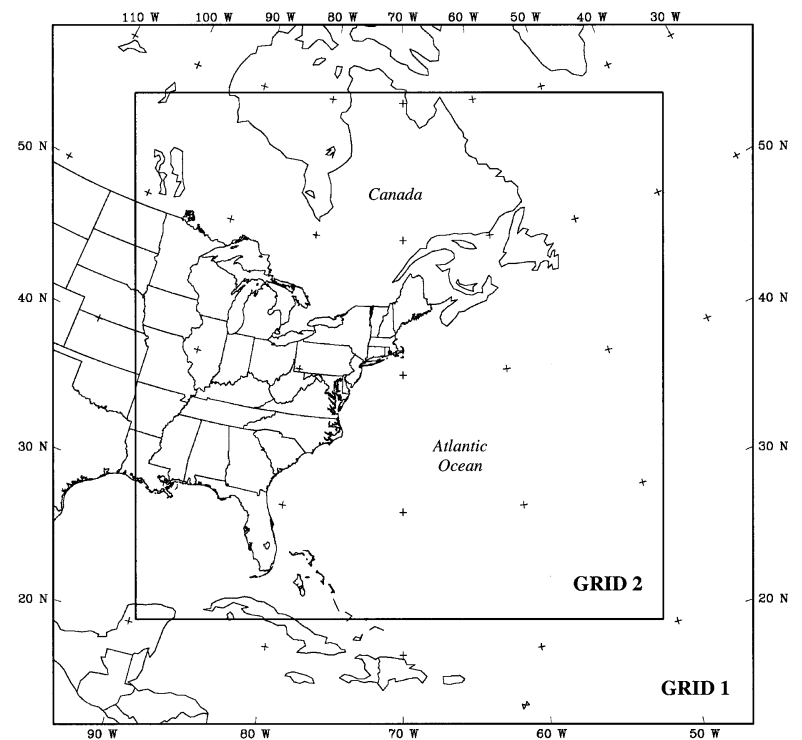

FIG. 3. Domains for the companion MM5 simulations. Grid 1 has a horizontal grid spacing of $60 \mathrm{~km}$, while Grid 2 has a grid spacing of $20 \mathrm{~km}$.

of MM5 model dynamics may be found in Grell et al. (1994).

Initialization fields and boundary conditions for both the FP and NLHR simulations are obtained from a global European Centre for Medium-Range Weather Forecasts (ECMWF) analysis dataset on a $2.5^{\circ} \times 2.5^{\circ}$ horizontal grid. Requisite 2D and 3D variables are horizontally interpolated to the MM5's Lambert conformal grid, while all 3D prognostic variables are vertically interpolated from 17 isobaric levels to the MM5 sigma levels. The initial-time analysis data are enhanced with observations from the standard network of surface and radiosonde stations using a successive-scan Cressman technique. Each 48-h simulation is initialized at 0000 UTC 31 March 1997, and boundary conditions are updated on the coarse mesh at every time step, with fields time interpolated from 12-hourly ECMWF analyses. The inner-mesh boundaries are updated at each time step with output from the outer mesh. The MM5's nudging four-dimensional data assimilation scheme was not used in either simulation.

\section{b. FP simulation evaluation}

As most of the subsequent analyses of the companion simulations will center on the structure of the occluded quadrant of the 1 April cyclone, a limited evaluation focused on the trowal structure in the postmature stage of the FP simulation is offered here. Examination of the cyclone life cycle revealed that the trowal structure first manifested itself at approximately 1800 UTC 31 March, reaching full maturity between 0000 and 1200 UTC 1 April. Figure 4 presents a comparison between the observed and modeled cloud distributions valid at $\sim 0800$
UTC 1 April. Top-of-the-atmosphere infrared fluxes in the MM5 (Fig. 4b) were computed directly from the model's RRTM radiation parameterization and include the effects of absorption by clouds and atmospheric gases. Although the integrated longwave flux is not an exact surrogate for the Geostationary Operational Environmental Satellite-8 (GOES-8) 6.7- $\mu \mathrm{m}$ infrared brightness temperatures (Fig. 4a), it nonetheless provides a useful product by which comparison between the distribution of cloud in MM5 with observations can be made. The extent and orientation of the cloud shield in the occluded quadrant in the FP simulation agrees well with the observations, though the modeled cloudiness in the occluded quadrant is located slightly to the north and west of the true feature.

The actual position of the trowal may be compared more objectively through comparison of the modeled and analyzed thermal structure. In his examination of the QG forcing for ascent in the occluded quadrant of this storm, Martin (1999a) showed that the 312-K $\theta_{e}$ surface offers a clear picture of the trowal structure in this storm. To this end, comparisons of the $312-\mathrm{K} \theta_{e}$ isosurface and a vertical cross section through the warm occlusion from the FP simulation and the Eta analysis are presented in Fig. 5. At 0000 UTC 1 April, the analysis and 24-h forecast from the FP simulation both place the trowal over southern New England, with a southeastward extension to the surface southeast of Cape Cod, Massachusetts (Figs. 5a,b). The agreement is equally gratifying in companion vertical cross sections through the trowal at this time (Figs. 5c,d). The fidelity is not quite as fine $12 \mathrm{~h}$ later (not shown), as the trowal position intersects the surface farther east in the analysis than it does in the 36-h forecast. Even then, however, both the analysis and forecast depict a trowal structure over southeastern New England.

\section{c. Specifications for the NLHR simulation}

In order to examine the effect of latent heat release on the development of the occluded thermal structure in this storm, a companion NLHR MM5 simulation was run. Removing the effects of latent heating associated with the phase change of water was accomplished by setting only the temperature tendency terms in the microphysics module equal to zero in the NLHR simulation. Additionally, because a primary function of the cumulus parameterization is to represent the effects of subgrid-scale latent heating on the modeled temperature profile, the Grell cumulus scheme was turned off. As the simulation progressed, the only diabatic temperature tendency terms computed in the model were those associated with the interaction of short- and longwave radiation with clouds and clear air and with surface fluxes of sensible and latent heat at the land and ocean surface. Thus, apart from the exclusion of LHR in the microphysics routine and the absence of a cumulus parameterization, the NLHR simulation was executed us- 



FIG. 4. (a) GOES-8 6.7- $\mu \mathrm{m}$ IR satellite picture from 0800 UTC 1 Apr 1997. (b) MM5 32-h forecast top-of-theatmosphere longwave radiative fluxes valid at 0800 UTC 1 Apr 1997. 

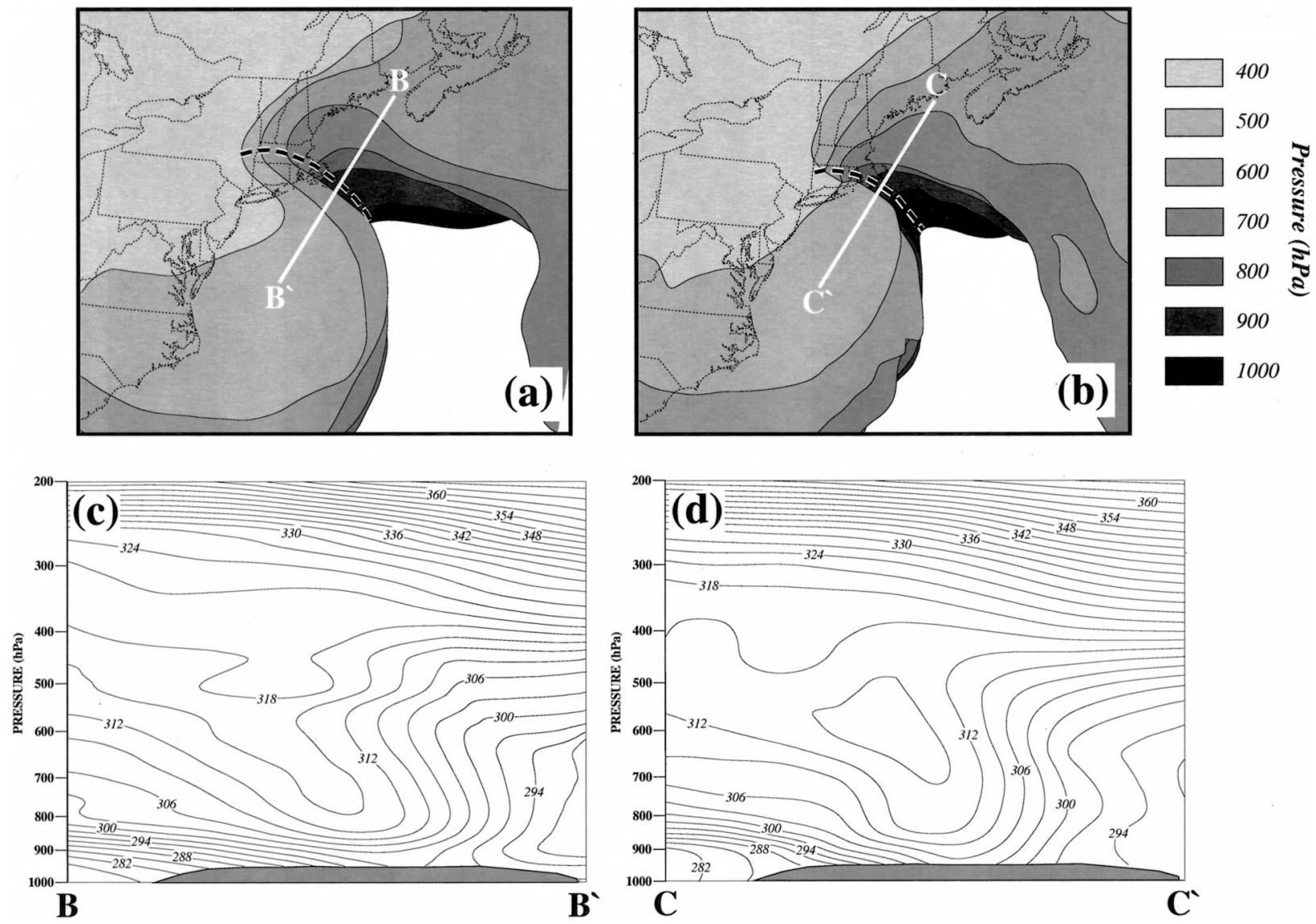

FIG. 5. (a) Isobaric topography of the 312-K $\theta_{e}$ surface from NCEP's Eta Model analysis valid at 0000 UTC 1 Apr 1997. Isobars are shaded at 100-hPa intervals from 1000 to $400 \mathrm{hPa}$. Bold dashed line indicates the position of the trowal. Vertical cross section along line B-B' is shown in (c). (b) As in (a), but for the 24-h forecast from the FP MM5 simulation valid at 0000 UTC 1 Apr 1997. Vertical cross section along line $\mathrm{C}^{-\mathrm{C}^{\prime}}$ is shown in (d). (c) Vertical cross section along line B-B' in (a) of $\theta_{e}$ from the Eta Model analysis valid at 0000 UTC 1 Apr 1997. (d) Vertical cross section along line $\mathrm{C}^{-\mathrm{C}^{\prime}}$ in (b) of $\theta_{e}$ from the 24-h forecast from the FP MM5 simulation valid at 0000 1 Apr 1997. In (c) and (d), moist isentropes (K) are contoured every $3 \mathrm{~K}$.

ing the same set of physical parameterizations as the FP run.

\section{Comparison of FP and NLHR simulations}

\section{a. Sea level pressure}

The positions of the SLP minima in both the FP and NLHR simulations are shown in Fig. 6. The paths are quite similar through 1200 UTC 31 March, by which time very little development had occurred. After this time the cyclogenesis is rather rapid, with the FP cyclone developing farther northward and more intensely than the NLHR storm. The period of vigorous cyclogenesis that begins after 1200 UTC 31 March is coincident with the arrival of a significant upper-tropospheric PV anomaly over coastal North Carolina at that time (not shown). A complete examination of the physical differences that forced the FP and NLHR cyclones to develop along separate paths is beyond the scope of this paper. It is evident, however, that the large synopticscale forcings conspiring to produce the developments in the two simulations were quite similar. Evidence for this assertion comes from a comparison of the columnaveraged $\mathbf{Q}$ vectors and their convergence at a representative time in the cyclone life cycle.

\section{b. Quasigeostrophic forcing}

Figure 7a shows the 500-900-hPa column-averaged $\mathbf{Q}$ vectors and their convergence, along with the sea level isobars, from the NLHR simulation at 0600 UTC 1 April 1997. The largest component of the total $\mathbf{Q}$ forcing is located to the north and northeast of the sea level pressure minimum. A rather similar distribution of QG forcing at 0600 UTC 1 April is evident in the FP simulation (Fig. 7b). Further partitioning of the total Q convergence field (not shown) demonstrated that, in both simulations, the most significant contribution to the total forcing is made by cyclonic vorticity advection by the thermal wind. In both simulations that component of the forcing was located just north and northeast of the surface cyclone center. 


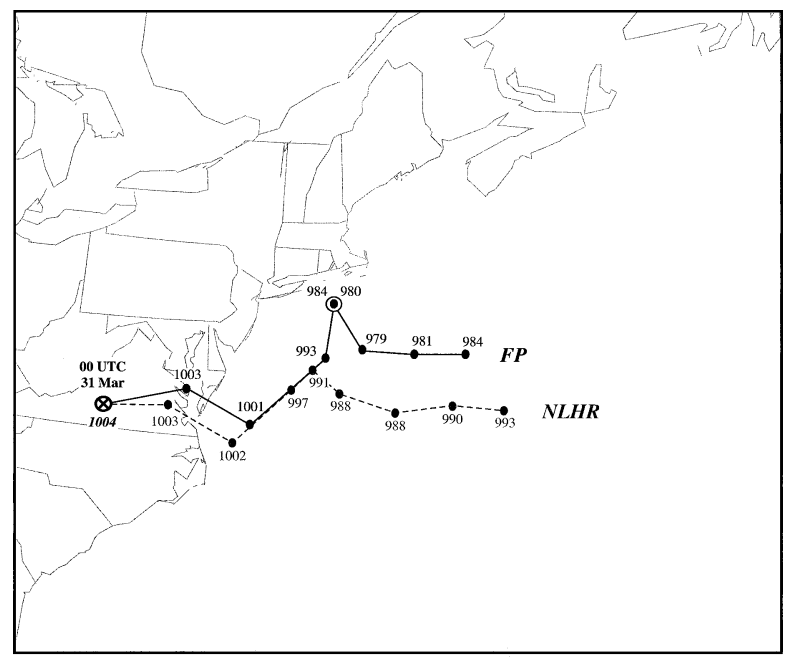

FIG. 6. Comparison of the tracks of the SLP minima from the FP and NLHR simulations. Solid black (gray) circles represent positions of the FP (NLHR) SLP minimum at 6-h intervals beginning at 0000 UTC 31 Mar 1997. Circled " $X$ " represents the initial-time position of the SLP minima in both simulations. Black circle with an open circle around it indicates the position of the FP SLP minimum at both 0000 and 0600 UTC 1 Apr 1997. Numbers next to dots report the SLP minimum $(\mathrm{hPa})$ for the given simulation at the given time.

\section{c. Occluded thermal structure}

Although both agree well with respect to synopticscale forcing for development, a comparison of the thermal structures of these two simulations begins to reveal differences. By 0600 UTC 1 April, both storms exhibit a lower-tropospheric occluded thermal ridge connecting the SLP minimum to the peak of the original warm sector (Fig. 8). Given that the character of the lowertropospheric circulations in both simulations was similar, it is not surprising that both developed similarlooking near-surface thermal ridges, as the respective circulations would have acted to deform the background lower-tropospheric gradients in saturated equivalent potential temperature ${ }^{2}\left(\theta_{\mathrm{es}}\right)$ in similar ways.

Vertical cross sections through the occluded thermal ridges in both simulations, however, begin to illustrate the significant differences between them. Figure 9a is a cross section of $\theta_{\text {es }}$, along line $\mathrm{A}-\mathrm{A}^{\prime}$ in Fig. 8a, from the NLHR simulation. Note the shallow warm front and the absence of a deep occluded structure in this section; there is only a very shallow axis of maximum $\theta_{\mathrm{es}}$ sloping upward and northward from the surface $\theta_{\mathrm{es}}$ ridge up to $600 \mathrm{hPa}$. In contrast, a vertical cross section from the

\footnotetext{
${ }^{2}$ In the NLHR simulation, rising saturated air parcels experience a reduction in moisture content without a corresponding temperature increase. Therefore, in order to compare the thermal structures in the occluded quadrants of the FP and NLHR simulations, we use saturated equivalent potential temperature $\left(\theta_{\mathrm{es}}\right)$ as the thermodynamic variable. Mathematically, $\theta_{\mathrm{es}}=\theta_{e}^{l_{s} L / T c_{p}}$, where $L$ is the latent heat of vaporization, $l_{s}$ is the saturation mixing ratio at $T$ and $p$, and $c_{p}$ is the specific heat of dry air at constant pressure; $\theta_{\mathrm{es}}$, unlike $\theta_{e}$, is conserved in the saturated updrafts of the NLHR simulation.
}

FP simulation (Fig. 9b), taken in the same system-relative location, ${ }^{3}$ shows the canonical, deep occluded thermal structure with a tropospheric-deep axis of maximum $\theta_{\mathrm{es}}$ sloping upward and northward from the surface $\theta_{\mathrm{es}}$ ridge up to $300 \mathrm{hPa}$. The fact that the $\theta_{\mathrm{es}}=303 \mathrm{~K}$ moist isentrope in the FP simulation (Fig. 9b) looks very similar to its counterpart in the NLHR simulation provides the first indication that the mid- and upper-tropospheric portions of the canonical occluded thermal structure are only present in the FP simulation.

The 3D structure of the trowal can be revealed through interrogation of the isobaric topography of a $\theta_{\text {es }}$ surface that lies close to the warm edge of the warm frontal and cold frontal baroclinic zones of an occluded thermal structure. Figure 9a suggests that the $\theta_{\mathrm{es}}=303$ $\mathrm{K}$ surface is an appropriate choice for the NLHR simulation, while in the FP simulation, an appropriate choice is the $\theta_{\mathrm{es}}=315 \mathrm{~K}$ surface (Fig. 9b). Comparison of these isosurfaces in the two simulations reinforces this initial impression. As early as 1800 UTC 31 March, the NLHR simulation exhibits only a lower-tropospheric trowal structure, as the $550-\mathrm{hPa}$ isobar clearly does not indicate the presence of a $\theta_{\text {es }}$ ridge at mid- and uppertropospheric levels (Fig. 10a). In contrast, the FP simulation is characterized by an axis of maximum $\theta_{\mathrm{es}}$ extending southward from Cape Cod (Fig. 10e). Not until 0600 UTC 1 April, when a shallow and poorly developed trowal is evident, does the NLHR simulation provide any evidence of a warm axis above $650 \mathrm{hPa}$ (Fig. 10c). The FP simulation, however, was characterized by a well-developed, deep trowal structure by this time (Fig. 10g). Given these differences between the simulations, which persist through 1200 UTC 1 April (Figs. $10 \mathrm{~d}, \mathrm{~h})$, it appears that the presence of a deep tropospheric warm occluded structure is strongly dependent on the release of latent heat.

\section{d. Tropopause structure}

As noted previously, a treble clef structure in the upper-tropospheric PV is indicative of an underlying warm occluded structure. Thus, comparison of the evolution of the upper-tropospheric PV between the NLHR and FP simulations offers further insight into the differences in their respective tropospheric thermal structures. As suggested by Fig. 9, the companion simulations described here were characterized by quite different tropopause potential temperatures. Thus, in order to make a fair comparison of tropopause structure between them, we examine their respective distributions of $\theta$ on the dynamic tropopause (defined here as the 1.5-PVU surface). As noted by Morgan and NielsenGammon (1998), local maxima in $\theta$ on such "tropo-

\footnotetext{
${ }^{3}$ Both cross sections are located $\sim 350 \mathrm{~km}$ east of their respective sea level pressure minima, along the axis of their respective thermal ridges, and are locally perpendicular to their respective thermal ridge axes.
} 

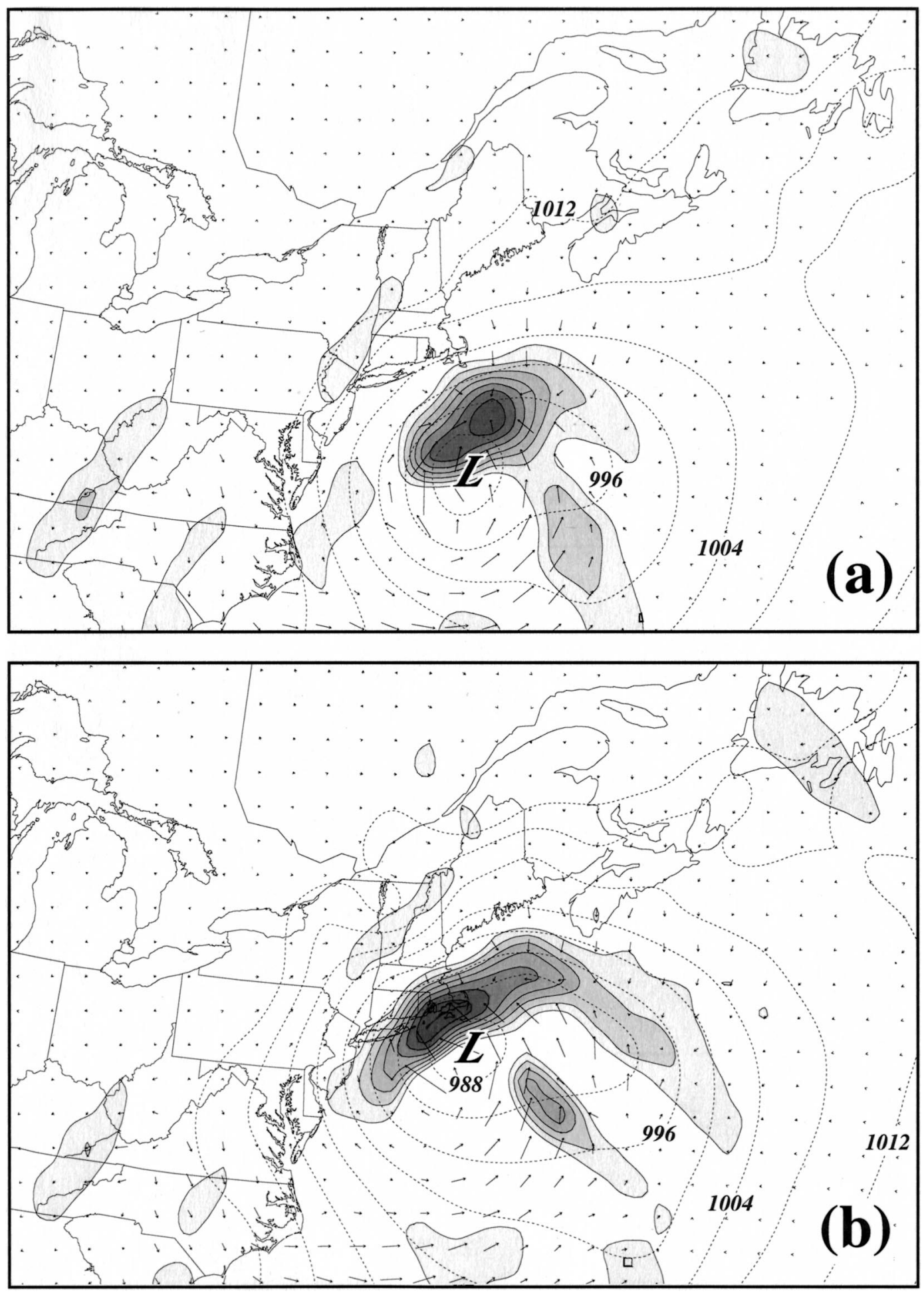

FIG. 7. (a) The 30-h MM5 forecast of column-averaged $\mathbf{Q}$ vectors and $\mathbf{Q}$ convergence in the $500-900-\mathrm{hPa}$ layer valid at 0600 UTC 1 Apr 1997 from the NLHR simulation. Dashed lines are sea level isobars (hPa) contoured every $4 \mathrm{hPa}$ up to $1012 \mathrm{hPa}$. Starting at $5 \times 10^{-15} \mathrm{~m} \mathrm{~kg}^{-1} \mathrm{~s}^{-1}, \mathbf{Q}$ convergence is shaded and contoured every $10 \times 10^{-15} \mathrm{~m} \mathrm{~kg}^{-1}$ $\mathrm{s}^{-1}$. Bold "L" indicates the location of the SLP minimum. (b) As in (a), except taken from the FP simulation. 

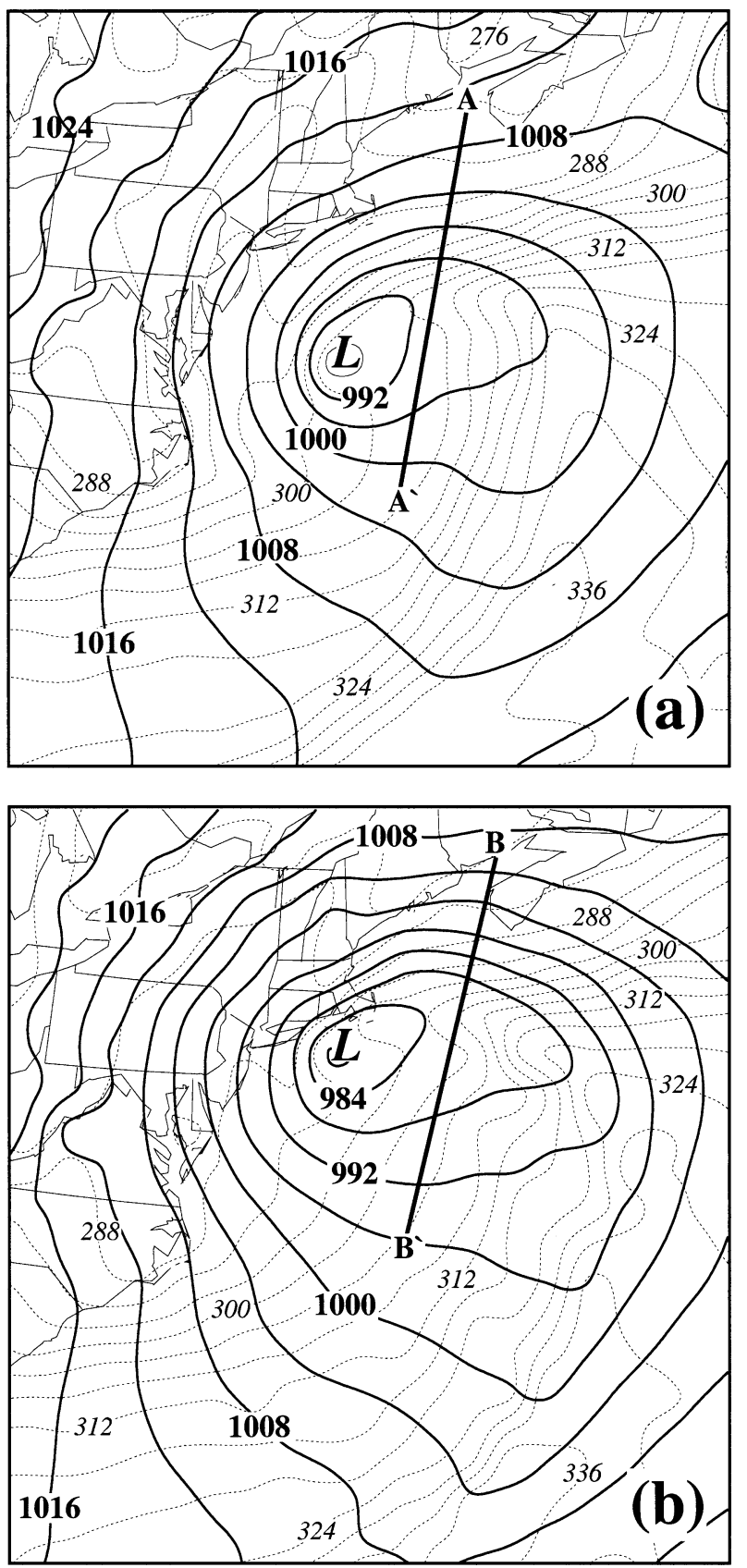

FIG. 8. (a) Sea level pressure and 950-hPa saturated equivalent potential temperature $\left(\theta_{\mathrm{es}}\right)$ at 0600 UTC 1 Apr 1997 from the NLHR simulation. Isobars $(\mathrm{hPa})$ are contoured every $4 \mathrm{hPa}$ and $\theta_{\mathrm{es}}(\mathrm{K})$ is contoured every $4 \mathrm{~K}$. Bold " $\mathrm{L}$ " represents the location of the SLP minimum. (b) As in (a), but for the FP simulation at 0600 UTC 1 Apr 1997. Lines $A-A^{\prime}$ and $B-B^{\prime}$ represent cross sections shown in Fig. 9.

pause maps" correspond to local minima in upper-tropospheric $\mathrm{PV}$, while regions of especially low $\theta$ correspond to local maxima in upper-tropospheric PV or, sometimes, to lower-tropospheric maxima in PV.

Figure 11 shows the tropopause maps from both simulations at 6-h intervals from 1800 UTC 31 March to
1200 UTC 1 April. Pronounced differences in the tropopause $\theta$ distribution begin to appear by 0000 UTC 1 April (Figs. 11b,f) over southern New England, where a much warmer tropopause appears in the FP simulation. By 0600 UTC 1 April, the tropopause $\theta$ ridge (i.e., the equivalent of the low-PV "notch" of the PV treble clef) is much better developed in the FP simulation (Fig. 11g) over central New England and eastern New York than it is over southern New England in the NLHR simulation (Fig. 11c). Also, a substantial lower-tropospheric PV feature is indicated by the presence of the $290-\mathrm{K}$ isentrope over southern New England, New York, and New Jersey. Interestingly, the tropopause $\theta$ treble clef in the NLHR simulation at this time bears some resemblance to the FP structure from $6 \mathrm{~h}$ earlier (Fig. 11f). Six hours later, an even better developed treble clef is evident in the FP simulation (Fig. 11h), along with a considerable expansion of the anomalous lower-tropospheric PV (Fig. 11h). The absence of LHR results in a tropopause with substantially lower $\theta$ over southern New England in the NLHR simulation (Fig. 11d) as well as a delayed, and less intense, development of a tropopause $\theta$ treble clef. In summary, it is clear that the FP simulation has a much higher $\theta$ at its tropopause, as well as a substantial lower-tropospheric PV feature, in the vicinity of the clouds and precipitation associated with the occluded quadrant of the cyclone.

\section{Development of the tropopause PV notch}

The thermal ridge in the FP simulation's tropopause $\theta$ developed most rapidly in the $18 \mathrm{~h}$ beginning at 1800 UTC 31 March (Fig. 11). It is the central hypothesis of this study that the release of latent heat associated with cloud and precipitation production in the occluded quadrant of the cyclone was a primary factor that led to this rapid structural transformation. There are two physical mechanisms that might link LHR to the development of the low-PV notch in the upper-tropospheric PV structure. One mechanism is essentially kinematic, relying upon the circulation associated with diabatically generated PV to distort the upper-tropospheric PV contours into the treble clef notch. The other mechanism is nonconservative and involves direct dilution of upper-tropospheric PV through diabatic "destruction" of PV. In this section we use output from the FP simulation to examine both possibilities, beginning with the former.

\section{a. Kinematic influence of the circulation associated with the diabatic $P V$}

Two properties of the Ertel PV (Rossby 1940; Ertel 1942; Hoskins et al. 1985) make it particularly appealing as a diagnostic tool for examining aspects of the cyclone life cycle: conservation and invertibility. The conservation principle states that in the absence of turbulent diffusion, frictional dissipation, or diabatic heating, the $\mathrm{PV}$ is conserved following the motion. This circum- 

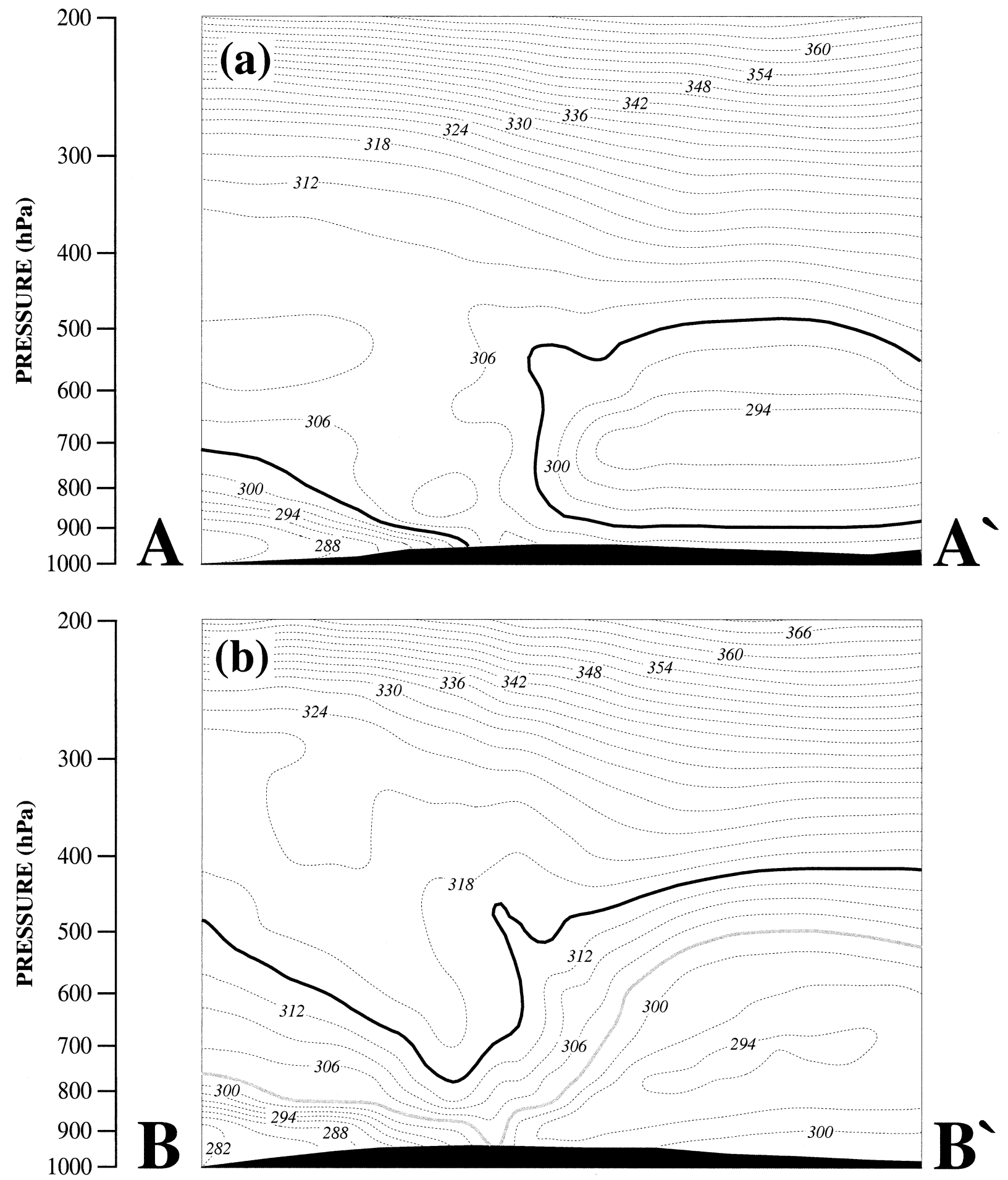

FIG. 9. (a) Cross section along line A-A' in Fig. 8a of saturated equivalent potential temperature $\left(\theta_{\text {es }}\right)$ from the 30 -h forecast of the NLHR simulation. Bold line is the $303-\mathrm{K}$ saturated moist isentrope, and $\theta_{\mathrm{es}}(\mathrm{K})$ is contoured every $3 \mathrm{~K}$. (b) As in (a), but from the 30-h forecast of the FP simulation taken along line $\mathrm{B}-\mathrm{B}^{\prime}$ in Fig. 8b. Bold black (gray) line is the 315 (303) K saturated moist isentrope. 
NLHR

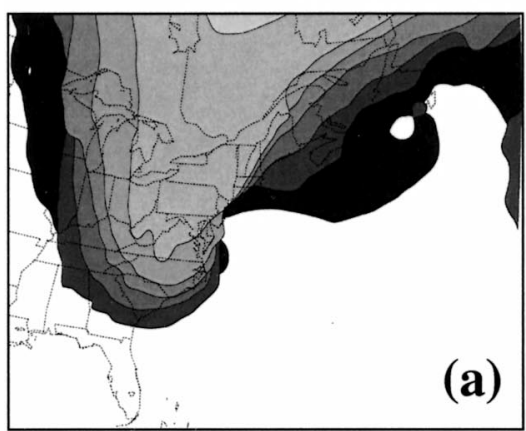

f18
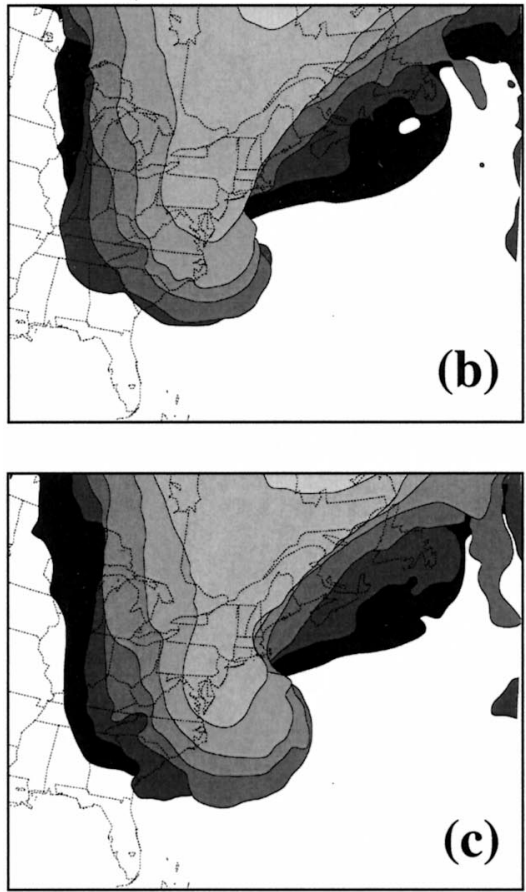

f30

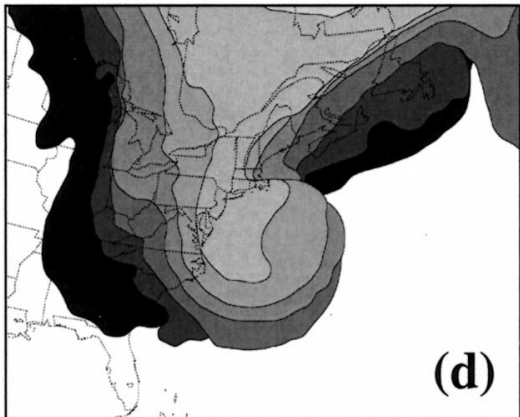

f36
FP
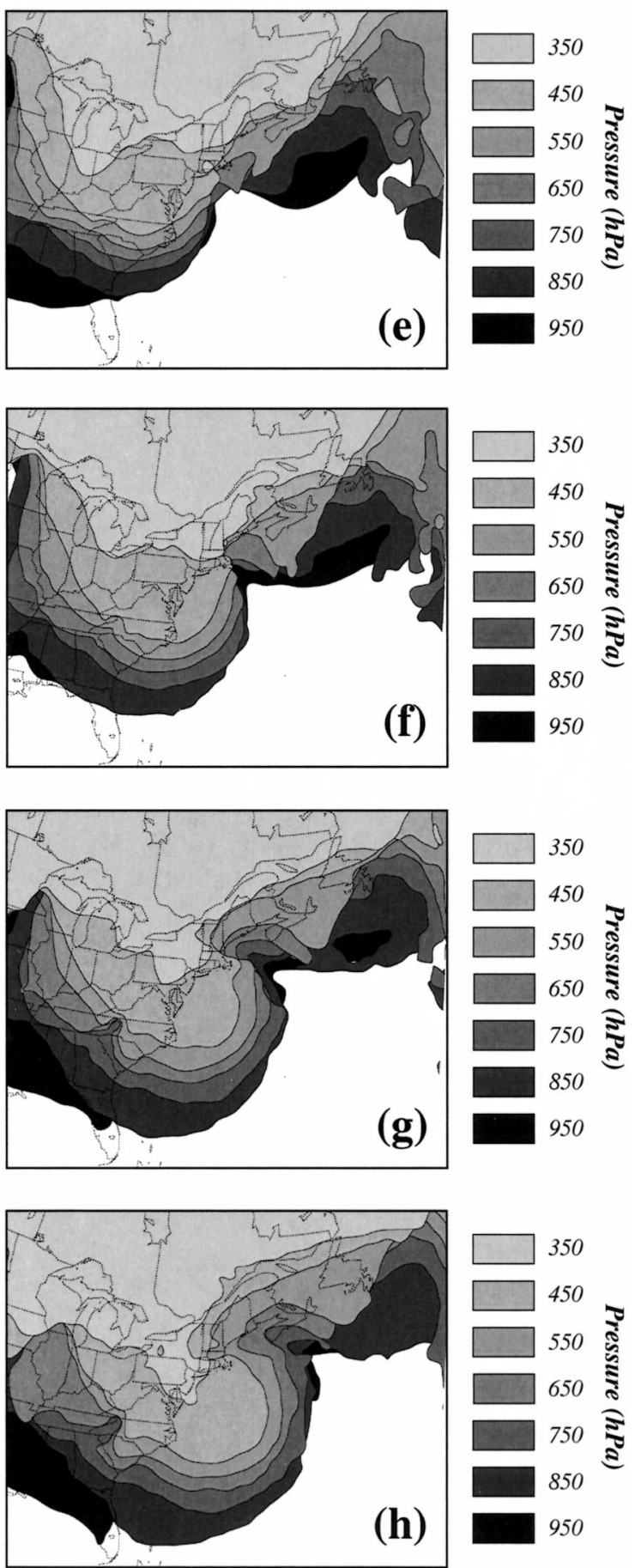

FIG. 10. Isobaric topography of the $\theta_{\mathrm{es}}=303 \mathrm{~K}$ surface at (a) $1800 \mathrm{UTC} 31 \mathrm{Mar}$ (b) $0000 \mathrm{UTC} 1 \mathrm{Apr}$, (c) $0600 \mathrm{UTC} 1 \mathrm{Apr}$, and (d) 1200 UTC 1 Apr 1997, from the NLHR simulation and Isobaric topography of the $\theta_{\mathrm{es}}=315 \mathrm{~K}$ surface at (e) 1800 UTC $31 \mathrm{Mar}$, (f) 0000 UTC 1 Apr, (g) 0600 UTC 1 Apr, and (h) 1200 UTC 1 Apr 1997 from the FP simulation. Isobars (hPa) are contoured and shaded every $100 \mathrm{hPa}$ beginning at $950 \mathrm{hPa}$. 
NLHR
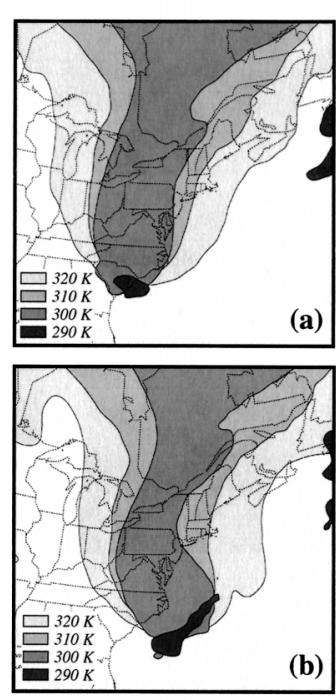

(a)

f18

$f 24$

(b)
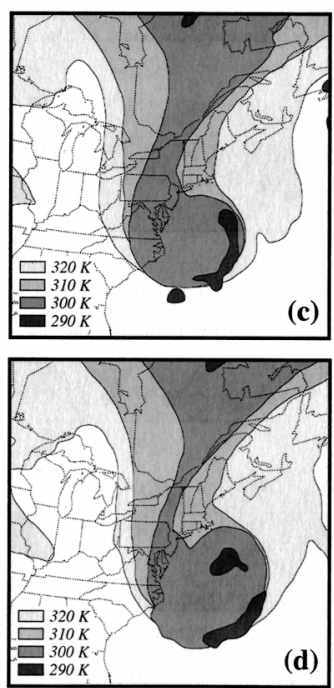

FP

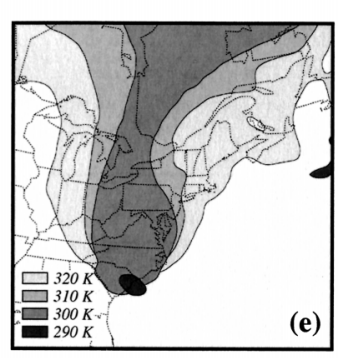

(e)

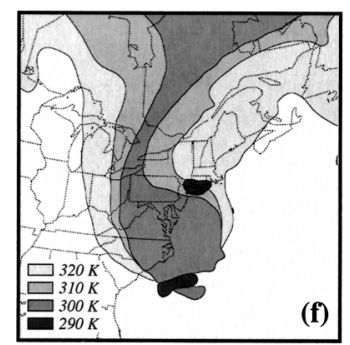

(f)
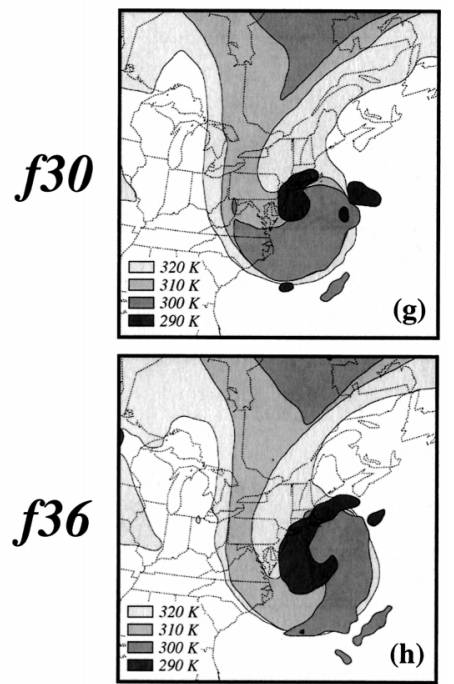

FIG. 11. (a) The 18-h forecast of potential temperature on the 1.5PVU surface from the NLHR simulation valid at 1800 UTC 31 Mar 1997. (b) As in (a), but for 24-h forecast valid at 0000 UTC 1 Apr 1997. (c) As in (a), but for 30-h forecast valid at 0600 UTC 1 Apr 1997. (d) As in (a), but for 36-h forecast valid at 1200 UTC 1 Apr 1997. (e) The 18-h forecast of potential temperature on the 1.5-PVU surface from the FP simulation valid at 1800 UTC 31 Mar 1997. (f) As in (e), but for 24-h forecast valid at 0000 UTC 1 Apr 1997. (g) As in (e), but for 30-h forecast valid at 0600 UTC 1 Apr 1997. (h) As in (e), but for 36-h forecast valid at 1200 UTC 1 Apr 1997. Isentropes (K) are contoured and shaded every $10 \mathrm{~K}$ from 290 to 320 $\mathrm{K}$, with light (dark) shading indicating higher (lower) $\theta$.

stance serves the purposes of the present study nicely as it provides a quantitative means of determining the portion of the total PV field at any time that is a direct result of diabatic heating. The invertibility principle states that knowledge of the PV distribution in a given domain, a suitable set of boundary conditions for that domain, and a so-called balance condition that relates the mass and momentum fields is sufficient to recover

the full kinematic and thermodynamic structure of the atmosphere in that domain. Davis and Emanuel (1991, hereafter DE) produced a functioning scheme, based upon Charney (1955) nonlinear balance, for inversion of the full Ertel PV. The scheme is based upon the assumption that (a) the atmosphere is in hydrostatic balance and (b) the irrotational wind is much smaller than the nondivergent wind. Davis and Emanuel also presented a method for piecewise PV inversion that allows recovery of the flow corresponding to discrete pieces of the PV distribution. In the present study we used the piecewise PV inversion scheme of DE to recover the flow field associated with the diabatically generated PV. The particular specifications of the DE scheme implemented here, including employment of relative humidity $(\mathrm{RH})$ criteria and a time mean, are similar to those described in Korner and Martin (2000) and Martin and Marsili (2002). As in those studies, our piecewise PV inversion proceeds from a conventional three-way partitioning of the total perturbation PV field into an upper layer $\left(U_{\text {pert }}\right)$, an interior layer $\left(M_{\text {pert }}\right)$, and a surface layer $\left(L_{\text {pert }}\right)$ designed to isolate $\mathrm{PV}$ anomalies at the tropopause, those associated with latent heat release, and those associated with lower boundary $\theta$ anomalies, respectively. The $U_{\text {pert }} \mathrm{PV}$ is defined as the perturbation $\mathrm{PV}$ in air with RH less than $80 \%$ in the $900-50-\mathrm{hPa}$ layer. The $M_{\text {pert }} \mathrm{PV}$ consists of the perturbation PV in air with $\mathrm{RH} \geq 80 \%$ in the $900-350-\mathrm{hPa}$ layer. Finally, the $L_{\text {pert }} \mathrm{PV}$ is composed of all perturbation $\mathrm{PV}$ in the 1000-950-hPa layer, along with the 1025 -hPa perturbation $\theta$. Since careful examination of the model output revealed no air with $\mathrm{RH} \geq 80 \%$ above $350 \mathrm{hPa}$, the foregoing partitioning accounts for all of the perturbation PV.

Figure 12 shows the 310-320-K layer averaged winds associated with the diabatically generated PV (hereafter referred to as the " $M_{\text {pert }}$ winds"), along with the PV isertels in that layer at 6-h intervals from 1800 UTC 31 March to 1200 UTC 1 April from the FP simulation. Note that the center of the upper-tropospheric $M_{\text {pert }}$ circulation at each time is distinctly anticyclonic and displaced to the east of the upper-tropospheric PV maximum. These two characteristics are consistent with the influence of LHR and the definition of $M_{\text {pert }}$. Latent heat release east of the upper-tropospheric PV maximum arises from the development of the cloud shield associated with the cyclone. Consistent with vertical redistribution of PV (a process described in the next section), heating concentrated in the middle troposphere acts to reduce PV in the upper troposphere (Raymond 1992). Air near the tops of the deepest clouds is characterized by both negative perturbation $\mathrm{PV}$ and $\mathrm{RH} \geq 80 \%$ and is therefore contained within $M_{\text {pert }}$. At 1800 UTC 31 March (Fig. 12a) there is substantial negative PV advection by the $M_{\text {pert }}$ winds along the southeast flank of the upper-tropospheric PV feature. Southern New England/southern New York, the region of imminent notch 

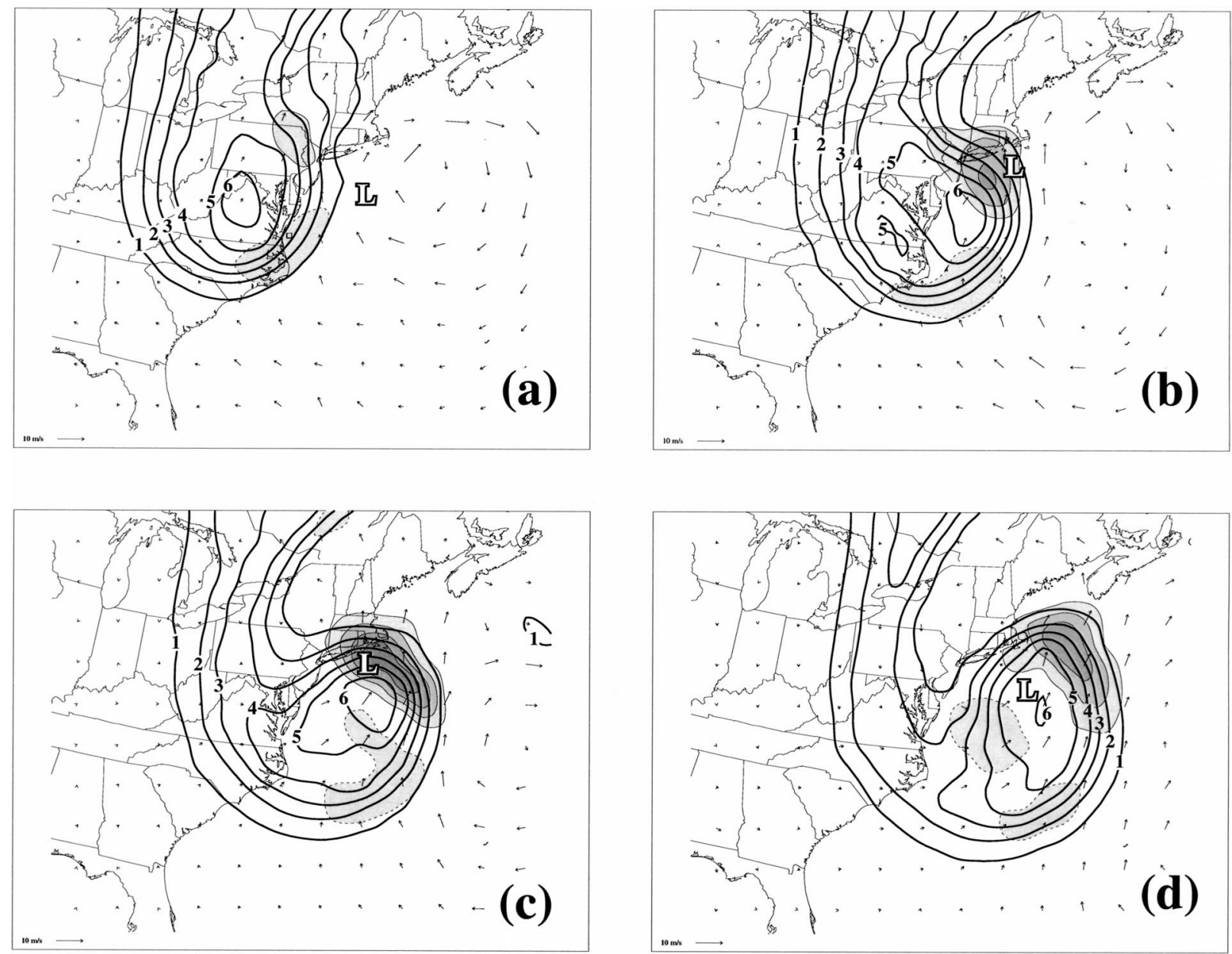

FIG. 12. (a) The 18-h FP MM5 forecast of column-averaged PV (solid lines), PV advection (shaded), and $M_{\text {pert }}$ winds in the 310-320 K isentropic layer valid at 1800 UTC 31 Mar 1997. (b) As in (a), but for 24-h forecast valid at 0000 UTC 1 Apr 1997. (c) As in (a), but for 30-h forecast valid at 0600 UTC 1 Apr 1997. (d) As in (a), but for 36-h forecast valid at 1200 UTC 1 Apr 1997. Potential vorticity (PVU; $1 \mathrm{PVU}=10^{-6} \mathrm{~m}^{2} \mathrm{~s}^{-1} \mathrm{~K} \mathrm{~kg}^{-1}$ ) is contoured every $1 \mathrm{PVU}$ beginning at $1 \mathrm{PVU}$. Negative (positive) advection [PVU (6h) $\left.{ }^{-1}\right]$ is contoured with dashed (solid) lines and shaded every $-0.5(0.5) \mathrm{PVU}(6 \mathrm{~h})^{-1}$ beginning at $-0.5(0.5) \mathrm{PVU}(6 \mathrm{~h})^{-1}$. Capital "L" indicates the location of the SLP minimum.

development, is characterized by slight positive PV advection by the $M_{\text {pert }}$ winds at this time.

By 0000 UTC 1 April, the notch in the treble clef had begun to develop over that region in spite of positive or neutral PV advection by the tropopause-level $M_{\text {pert }}$ winds (Fig. 12b). Continued substantial negative PV advection was occurring on the southern flank of the upper-level PV feature at this time. Interestingly, the more substantial positive PV advection by the $M_{\text {pert }}$ winds is nearly coincident with the position of the surface SLP minimum at this time and served to modestly accentuate the signature of the low-PV trough to its northwest. Six hours later, the picture is generally the same (Fig. 12c). Negative PV advection on the southern/ southeastern flank of the tropopause PV anomaly continued, as did the now stronger positive PV advection centered over the island counties of Massachusetts. By this time, the notch in the PV treble clef was quite well developed and had formed without the aid of negative PV advection by the $M_{\text {pert }}$ winds.

Finally, by 1200 UTC 1 April, a discernible but weak cyclonic, tropopause-level $M_{\text {pert }}$ circulation appeared centered near Long Island, New York. Partly as a consequence of this flow feature, some negative PV advection by the $M_{\text {pert }}$ winds was coincident with the axis of the robust notch feature (Fig. 12d). The magnitude of this negative PV advection, however, falls below the threshold for shading in the figure.

Analysis of Fig. 12 clearly demonstrates that the upper-tropospheric winds associated with the diabatically produced PV did not result in negative PV advection into the developing notch in the treble clef PV structure. Though positive $M_{\text {pert }}$ PV advection east of New England served to accentuate the notch signature after 0000 UTC 1 April, the rapid southwestward progression of the nose of the notch through 1200 UTC 1 April cannot be at- 
tributed to $M_{\text {pert }}$ advection alone. Likewise, $M_{\text {pert }}$ advection is incapable of accounting for the initial formation of the notch between 1200 UTC 31 March and 0000 UTC 1 April. We therefore conclude that kinematic rearrangement of the upper-tropospheric PV by the circulation associated with diabatically generated PV was not responsible for the development of the notch in this case and consequently had little effect on the evolution of the trowal.

\section{b. Direct dilution of tropopause PV by LHR}

Following Hoskins et al. (1985), the rate of change of PV due to diabatic effects can be represented as

$$
\frac{d(\mathrm{PV})}{d t}=\frac{1}{\rho}\left(\boldsymbol{\eta}_{a} \cdot \nabla \dot{\theta}\right)
$$

where $\dot{\theta}$ is the rate of diabatic heating. Thus, differential diabatic heating in the direction of the absolute vorticity vector will result in nonconservation of $\mathrm{PV}$ such that midtropospheric diabatic heating in the Northern Hemisphere produces anomalously high (low) PV in the lower (upper) troposphere (Raymond 1992). In this section, the rate of LHR is explicitly calculated from the FP model output and is then used to compute the rate of change of PV in the column in order to determine if direct dilution of upper-tropospheric PV could have been a primary factor in notch development.

Following the method employed by Emanuel et al. (1987), the rate of latent heating can be calculated as

$$
H=\frac{d \theta}{d t}=\omega\left(\frac{\partial \theta}{\partial p}-\frac{\gamma_{m}}{\gamma_{d}} \frac{\theta}{\theta_{e}} \frac{\partial \theta_{e}}{\partial p}\right),
$$

where $d \theta / d t$ corresponds to LHR, $\omega$ is the vertical motion (omega), $\theta_{e}$ is the equivalent potential temperature, and $\gamma_{d}$ and $\gamma_{m}$ are the dry and moist adiabatic lapse rates, respectively. Quantitative values of PV dilution in the upper troposphere are obtained by inserting values of the calculated LHR into an explicit computation of the diabatic, nonadvective time tendency of PV. Following Cammas et al. (1994), the local nonadvective change in PV with time can be written as

$$
\frac{\partial \mathrm{PV}}{\partial t}=-g \boldsymbol{\nabla}_{p} \cdot \mathbf{Y}
$$

where $g$ is the gravitational acceleration, $\nabla_{p}$ is the threedimensional vector gradient $\left(\boldsymbol{\nabla}_{p}=\partial / \partial x \hat{\mathbf{i}}+\partial / \partial y \hat{\mathbf{j}}-\partial /\right.$ $\partial p \hat{\mathbf{k}})$, and $\mathbf{Y}$ is the nonadvective potential vorticity flux vector,

$$
\mathbf{Y}=-H \boldsymbol{\zeta}_{\alpha}+\nabla_{p} \theta \times \mathbf{F},
$$

where $\boldsymbol{\zeta}_{\alpha}$ is the three-dimensional absolute vorticity vector $\left(\zeta_{x}=\partial v / \partial p, \zeta_{y}=-\partial u / \partial p, \zeta_{p}+f\right)$ and $\mathbf{F}$ is the friction force. For the purposes of the present investigation, we neglect the effects of friction and focus solely on the time tendency of PV associated with LHR, which may be written as

$$
\frac{\partial \mathrm{PV}}{\partial t}=-g \boldsymbol{\nabla}_{p} \cdot \mathbf{Y}=g \boldsymbol{\zeta}_{\alpha} \cdot \boldsymbol{\nabla}_{p} H
$$

Since the mesoscale details of the field of LHR are not particularly relevant to the problem at hand and tend to add excessive noise to the diagnostics, a nine-point smoother was applied to the $20-\mathrm{km}$ output before calculations of PV dilution were made using (5). ${ }^{4}$

At 1800 UTC 31 March, modest negative PV tendencies were concentrated over New England, with larger values extending southward off the Atlantic seaboard (Fig. 13a). More significant PV dilution occurred by 0000 UTC 1 April over southern New England. This diabatic destruction had begun to produce a significant PV trough over southern New England by this time (Fig. 13b). Continued PV dilution in that region occurred through 0600 UTC 1 April (Fig. 13c) as the notch in the treble clef PV structure continued to grow. At this time, however, the negative PV tendencies were no longer coincident with the notch axis. This continued to be the case at 1200 UTC 1 April (Fig. 13d), by which time the notch had grown considerably. It appears, in fact, that the extensive notch growth from 0000 to 1200 UTC 1 April was somewhat divorced from the location of the most intense PV dilution. This circumstance suggests that some other mechanism may have contributed to the notch development during this interval.

The PV, full winds, and negative PV advection by the full winds (shaded) in the 310-320-K isentropic layer at 1800 UTC 31 March are shown in Fig. 13e. Very little negative PV advection was occurring at this time anywhere in the northeastern United States. Six hours later, although modest negative advection was occurring in south-central New York near the southwest edge of the modest notch in the PV, almost no negative PV advection was occurring over southern New England (Fig. 13f). By 0600 UTC 1 April, significant and localized negative PV advection was occurring over the Middle Atlantic states in the 310-320-K layer (Fig. $13 \mathrm{~g}$ ), precisely coincident with the location of the growing notch in the PV. Large negative advective PV tendencies continued through 1200 UTC 1 April (Fig. 13h) in the vicinity of the notch.

The preceding analysis highlights the combined effects of LHR and upper-tropospheric PV advection in the generation of the upper-tropospheric PV notch and motivates the following conceptual model for understanding the influence of LHR associated with clouds and precipitation on the development of an occluded thermal structure. In the open wave stage of the cyclone life cycle, significant ascent occurs in the near vicinity of the SLP minimum, which is located just downstream of an upper-tropospheric positive PV anomaly, as shown in schematic form in Fig. 14a. Given sufficient moisture,

\footnotetext{
${ }^{4}$ The calculations of PV dilution using (5) were carried out on isobaric surfaces and subsequently interpolated to isentropic surfaces for display.
} 
this ascent produces abundant LHR, which then serves to erode the tropopause PV through diabatic dilution. Some time later, persistent diabatic erosion of PV has formed a dent in the tropopause structure (i.e., the uppertropospheric PV notch) (Fig. 14b), which, coupled with the eastward propagation of the upstream ridge, initiates the isolation of the low-latitude, upper-tropospheric PV feature. The circulation associated with this PV feature then begins to contribute to negative PV tendency in the developing notch via negative PV advection, further isolating the low-latitude PV feature (Fig. 14c) and accelerating the cutoff process. In the underlying troposphere, the response to the development of the local upper-tropospheric PV minimum is the simultaneous development of an isolated, warm, weakly stratified column of air. Based along the near-surface thermal ridge, this column slopes poleward and westward, and its axis is identically the trowal. Based upon comparison of the FP and NLHR simulations, it appears that in the late stages of the cyclone life cycle, the characteristic lowertropospheric thermal ridge forms as the near-surface thermal wave crests in response to the kinematics of the lower-tropospheric circulation. Cutting off of the uppertropospheric PV wave, however, requires a synergistic interaction between tropopause-level kinematics and midtropospheric latent heat release to the north and west of the sea level pressure minimum. The net result of these processes is the production of the characteristic occluded thermal structure.

The fact that a slowly developing, weaker version of the tropopause $\theta$ treble clef evolves in the NLHR simulation (cf., e.g., Figs. 11a and 11d) suggests that there is some intrinsic adiabatic, kinematic tendency for this structure to form at the tropopause even in the absence of LHR. In fact, a similar feature appears in the tropopause maps characterizing the "life cycle 2" (LC2) described by Thorncroft et al. (1993). A signature of this kinematic tendency is revealed by considering the isentropic distribution of the vector quantity, $\mathbf{Q}_{\mathrm{PV}}$, defined as

$$
\begin{aligned}
\frac{d}{d t} \boldsymbol{\nabla}_{\theta} \mathrm{PV} & =\mathbf{Q}_{\mathrm{PV}} \\
& =\left[\left(-\frac{\partial \mathbf{V}}{\partial x} \cdot \boldsymbol{\nabla}_{0} \mathrm{PV}\right) \mathbf{i},\left(-\frac{\partial \mathbf{V}}{\partial y} \cdot \boldsymbol{\nabla}_{\theta} \mathrm{PV}\right) \mathbf{j}\right],
\end{aligned}
$$

where $\mathbf{Q}_{\mathrm{PV}}$ describes the adiabatic, frictionless rate of change of $\boldsymbol{\nabla}_{\theta} \mathrm{PV}$ on a $\theta$ surface. It is similar to the $\mathbf{Q}_{\mathrm{PV}}$ introduced by Davies and Rossa (1998), with the exception that (6) uses the full 2D wind on a $\theta$ surface and Davies and Rossa (1998) used the geostrophic wind on a $\theta$ surface.

Partitioning $\mathbf{Q}_{\mathrm{PV}}$ into its along- and across-isertel components, $\mathbf{Q}_{\mathrm{PVs}}$ and $\mathbf{Q}_{\mathrm{PVn}}$, renders expressions that separately describe the rate of change of direction and magnitude of $\nabla_{\theta} \mathrm{PV}$, respectively. Divergence of $\mathbf{Q}_{\mathrm{PV}}$ is easily shown to differentially rotate $\nabla_{\theta} \mathrm{PV}$ on either side of the divergence axis to produce a PV trough on a $\theta$ surface. Figure 15 shows the $300-310-\mathrm{K}$ isentropic PV along with $\mathbf{Q}_{\mathrm{PVs}}$ vectors and their divergence from the NLHR simulation at 6-h intervals from 1800 UTC 31 March to 1200 UTC 1 April. ${ }^{5}$ Note the persistent divergence of the $\mathbf{Q}_{\mathrm{PVs}}$ field in the vicinity of the modest PV notch that develops in the NLHR simulation. This divergence testifies to the presence of a background kinematic tendency for production of a treble clef structure in this case. The combination of such an adiabatic, kinematic tendency with persistent diabatic heating in the vicinity of the notch leads to much more rapid and robust development of the tropopause PV feature in the FP simulation. The direct consequences of this more robust, LHR-aided development is a deeper, more well developed occluded thermal structure in the underlying troposphere.

\section{Discussion}

As noted by Schultz and Mass (1993) in their review of prior studies on occluded fronts, a variety of opinions exist regarding the nature of the occlusion process. In the intervening 10 years, several studies (e.g., Mass and Schultz 1993; Reed et al. 1994; Martin 1998a, 1999a) have documented actual cases of occluded cyclones using output from finescale numerical simulations. Though many questions regarding the nature of occluded cyclones remain, synoptic experience demonstrates that as a cyclone occludes, a thermal ridge connecting the sea level pressure minimum to the triple point develops and lengthens with time. An occluded front is often analyzed as occupying the axis of the surface thermal ridge. Similar thermal ridges at midand upper-tropospheric levels also develop in the late stages of the cyclone life cycle. Thus, as shown in Fig. 1 , the axis of maximum $\theta\left(\theta_{e}\right)$ that characterizes the occluded thermal structure is a $3 \mathrm{D}$ entity that tends to slope poleward and westward. We contend that a general consensus regarding these characteristic elements of the thermal structure of occluded cyclones exists and that the trough of warm air aloft, or trowal, model succinctly represents these essential structural characteristics. We further propose that disputes regarding the "occlusion process" might be rectified by regarding it as the process(es) by which a cyclone acquires the characteristic trowal structure.

Observations of the coincidence of significant precipitation and upper-tropospheric PV minima in the occluded quadrant of postmature phase cyclones prompted the present examination of the role that latent heat release might play in the production of occluded thermal structures in cyclones. The present paper has compared the thermal structures of FP and NLHR simulations of the 1 April 1997 southern New England blizzard per-

\footnotetext{
5 The 300-310-K layer was the layer within which the dynamic tropopause (1.5-PVU surface) was located in the NLHR simulation.
} 

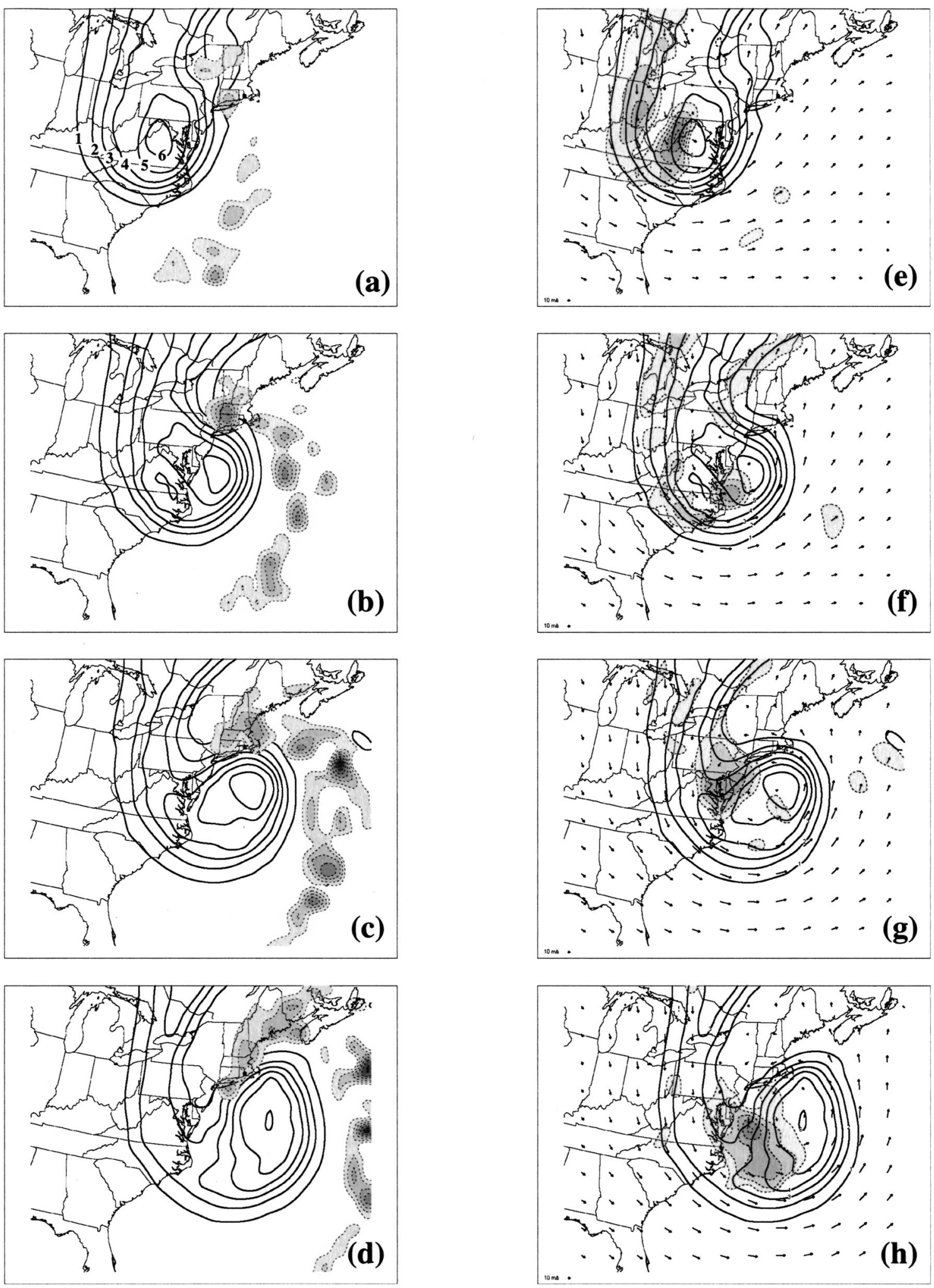

FIG. 13. (a) The 18-h forecast of PV and negative diabatic PV tendency in the 310-320-K isentropic layer at 1800 UTC 31 Mar 1997 from the FP simulation. Solid lines are isertels (PVU) and are labeled every 1 PVU. Negative diabatic PV tendency is shaded at intervals of -0.2 PVU $(6 \mathrm{~h})^{-1}$ beginning at $-0.2 \mathrm{PVU}(6 \mathrm{~h})^{-1}$. (b) As in (a), but for 24-h forecast valid at $0000 \mathrm{UTC} 1 \mathrm{Apr} 1997$. (c) As in (a), but for 30-h forecast valid at 0600 UTC 1 Apr 1997. (d) As in (a), but for 36-h forecast valid at 1200 UTC 1 Apr 1997. (e) Solid lines as in (a), with shading indicating negative advection of the $310-320-\mathrm{K}$ isentropic layer PV by the $310-320-\mathrm{K}$ isentropic layer winds. Winds are 
formed using the MM5. In the course of this research we have also examined similar companion simulations of two other occluded cyclones (The interested reader can view animations of output from these simulations at http://marrella.aos.wisc.edu/lhr/occlusion.html). In all three cases, troposphere-deep warm occluded thermal structures did not develop in the NLHR simulations, suggesting that latent heat release is a fundamental element of the occlusion process as defined above.

Simulations of observed occluded storms that bear mention in light of the results presented here include those of Kuo et al. (1992) and Reed et al. (1994). In the former case, a finescale simulation of the Ocean Ranger storm was performed using the hydrostatic mesoscale model, version 4 (MM4). A deep occluded thermal structure was evident in a cross section through the triple point (their Fig. 14), a region characterized by significant ascent and cloudiness. A considerably shallower occluded structure was present in a cross section perpendicular to the lower-tropospheric thermal ridge (their Fig. 15) in approximately the same system-relative location as $\mathrm{A}-\mathrm{A}^{\prime}$ (on Fig. 8a) in the present study. This cross section was located in the so-called dry slot of this storm and as a consequence was void of any latent heat release by virtue of the sustained subsidence that characterized that region. Their Fig. 15 is remarkably similar to our Fig. 9a in the shallow extent of the occluded thermal structure. Based upon the results of the present study, we suggest that the structural differences in the two cross sections through the occluded thermal ridge in Kuo et al. (1992) are a direct consequence of differences in latent heat release that characterized the two locations.

Reed et al. (1994) performed an adiabatic simulation of the Experiment on Rapidly Intensifying Cyclones over the Atlantic (ERICA) intensive observing period 4 (IOP-4) storm using the MM5. They found examples of classical-looking occluded structures (their Fig. 8c) characterized by large values of lower-tropospheric PV centered in the trowal, coupled with a clear tropopause PV minimum just poleward of it. In the absence of latent heat release, they speculated that the lower-tropospheric PV structure had its origin in diffusive fluxes of heat and momentum. The existence of such PV couplets in nature is most often the by-product of sustained latent heat release in the occluded quadrant of the cyclone (Davis et al. 1993; Stoelinga 1996; Pomroy and Thorpe 2000). Whatever its source in the model, it is our suggestion that such "production" of lower-tropospheric PV and accompanying "destruction" of upper-tropospheric PV is precisely the sufficient condition for pro- duction of a warm occluded thermal structure in the underlying troposphere.

Though a number of insights into the cyclone life cycle have arisen from idealized, adiabatic numerical simulations, few such studies have specifically examined the fully 3D occluded thermal structure. Those that have commented on occlusions have uniformly illustrated only the development of a lower-tropospheric thermal ridge that represents but one component of the full occluded thermal structure (e.g., Golding 1984; Takayabu 1986; Polavarapu and Peltier 1990; Davies et al. 1991; Thorncroft et al. 1993; Schultz et al. 1998). Only Polavarapu and Peltier (1990) show a vertical cross section through the occluded quadrant of their idealized cyclone (their Fig. 17b). Though that cross section shows elements of a characteristic occluded thermal structure, the model they employed in their study did not have a tropopause, so no fair comparison with our MM5 simulations is possible. A weak treble clef structure appears in the tropopause maps of Thorncroft et al. (1993) in their analysis of the LC2 life cycle. They showed that the LC2 life cycle evolution resulted from the imposition of large-scale, positive barotropic shear on the cyclogenetic environment. The similarity of their LC2 tropopause maps to those characterizing our NLHR simulation suggests that the large-scale environment in the present case was a significant factor in the development of the warm occluded thermal structure. Analysis of the along-isertel component of the diagnostic $\mathbf{Q}_{\mathrm{PV}}$ vector confirms the importance of the large-scale flow in promoting such development (see Fig. 15). The results of the present study, however, demonstrate that in the absence of LHR the canonical warm occluded thermal structure does not develop, suggesting that LHR is an equally important factor in the production of such structures. We therefore contend that both of these primary processes are correctly viewed as necessary, but insufficient, for producing the warm occluded thermal structures found in nature. The results presented here make clear that a solitary focus on the lower troposphere when assessing the presence or absence of an occluded structure can be misleading, as the structure is inherently 3D. Given the results of the present study, we suspect that any idealized, adiabatic cyclone simulation would likely exhibit only a shallow occluded structure, not the tropospheric-deep trowal structure characteristic of occluded cyclones in nature.

Recent work by Martin (1999a,b) has offered a dynamical explanation for the simultaneous development of the thermal ridge/trowal structure and the forcing for ascent in the occluded quadrant of cyclones. He found

$\leftarrow$

indicated by arrows. Negative PV advection in dashed lines [PVU (6h) ${ }^{-1}$ ] is shaded every -1 PVU (6h) ${ }^{-1}$ beginning at -1 PVU $(6 \mathrm{~h})^{-1}$. (f) As in (e), but for 24-h forecast valid at 0000 UTC 1 Apr 1997. (g) As in (e), but for 30-h forecast valid at 0600 UTC 1 Apr 1997. (h) As in (e), but for 36-h forecast valid at 1200 UTC 1 Apr 1997. 

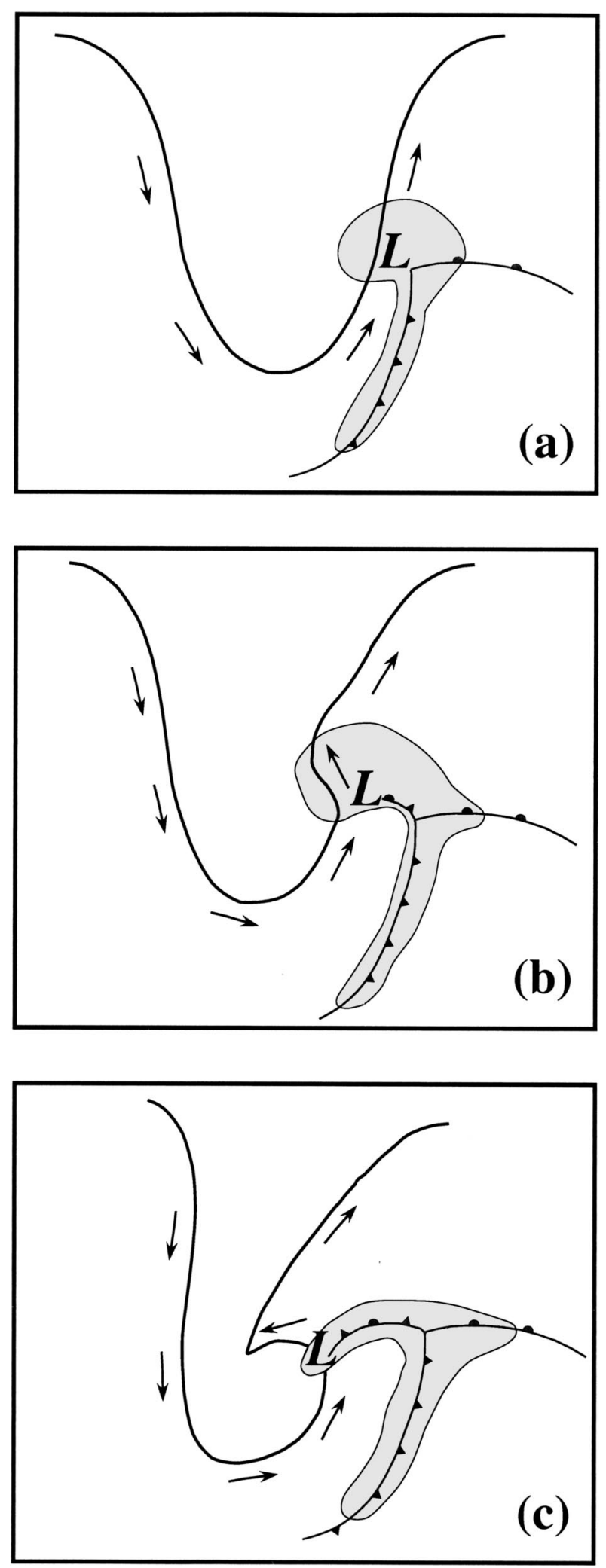

FIG. 14. Schematic illustrating the synergy between diabatic dilution of PV and negative advection of PV at the tropopause. Gray shading represents the dilution of tropopause PV by diabatic heating associated with the cyclone, the surface position of which is marked that the predominant QG forcing for ascent in the occluded quadrant was the convergence of the along-isentrope component of the $\mathbf{Q}$ vector, $\mathbf{Q}_{s}$. In the absence of latent heat release, the ascent associated with the $\mathbf{Q}_{s}$ convergence would lead to an adiabatic cooling of the air (i.e., vertical $\theta$ advection) in the thermal ridge, tending, therefore, to erode the warm anomaly defining that feature. If, as is the case in nature, the ascent is associated with latent heat release, a more durable thermal ridge structure results from the combination of the dynamic and diabatic forcings. Thus, our results suggest a view of the occlusion process that is as dependent on the characteristic dynamics in the occluded quadrant as it is on the latent heat release that results from the dynamical forcing.

\section{Conclusions}

The notion of occlusion of a midlatitude cyclone has been controversial since its introduction nearly 80 years ago. Despite a recent renewed research interest in the phenomenon and the availability of sophisticated numerical models with which to interrogate it, consensus is still lacking with respect to the nature of the occlusion process. Considerably greater agreement exists regarding the characteristic tropospheric thermal structure of a warm occluded cyclone. In the present paper we have taken advantage of that fact to argue from the premise that the occlusion process should be considered as the mechanism, or set of mechanisms, that acts to produce the characteristic occluded thermal structure in the troposphere.

In a recent investigation of an occluded cyclone made using the output from a finescale numerical simulation, Martin (1998a) noted that the upper-tropospheric PV morphology associated with the storm had a direct empirical and theoretical relationship to the thermal structure of the underlying troposphere. Specifically, he noted that since high (low) upper-tropospheric PV is characterized by a cold (warm) column of air beneath it, the treble clef shape to the upper-tropospheric PV illustrated in Fig. 2, is a sufficient condition for asserting the presence of an occluded structure in the underlying tropo-

$\leftarrow$

by the "L." Traditional surface frontal symbols indicate surface frontal locations. Thick solid line represents the PV $=2 \mathrm{PVU}$ isertel at the tropopause. Arrows represent the tropopause-level flow associated with the upper-tropospheric PV feature. (a) The open wave stage. Heating is concentrated along the cold front and in the vicinity of the developing surface cyclone. (b) Commencement of occlusion. Persistent diabatic dilution in the northwest quadrant of the cyclone deforms the upper-tropospheric PV contour northwest of the surface cyclone. Tropopause-level flow is also deformed in that vicinity. (c) Fully occluded stage. Cyclone is far removed from the peak of the surface warm sector. Heating is no longer proximate to the "notch" in the upper-tropospheric PV. Tropopause-level flow controls intensification of the notch through negative PV advection in the upper troposphere. 

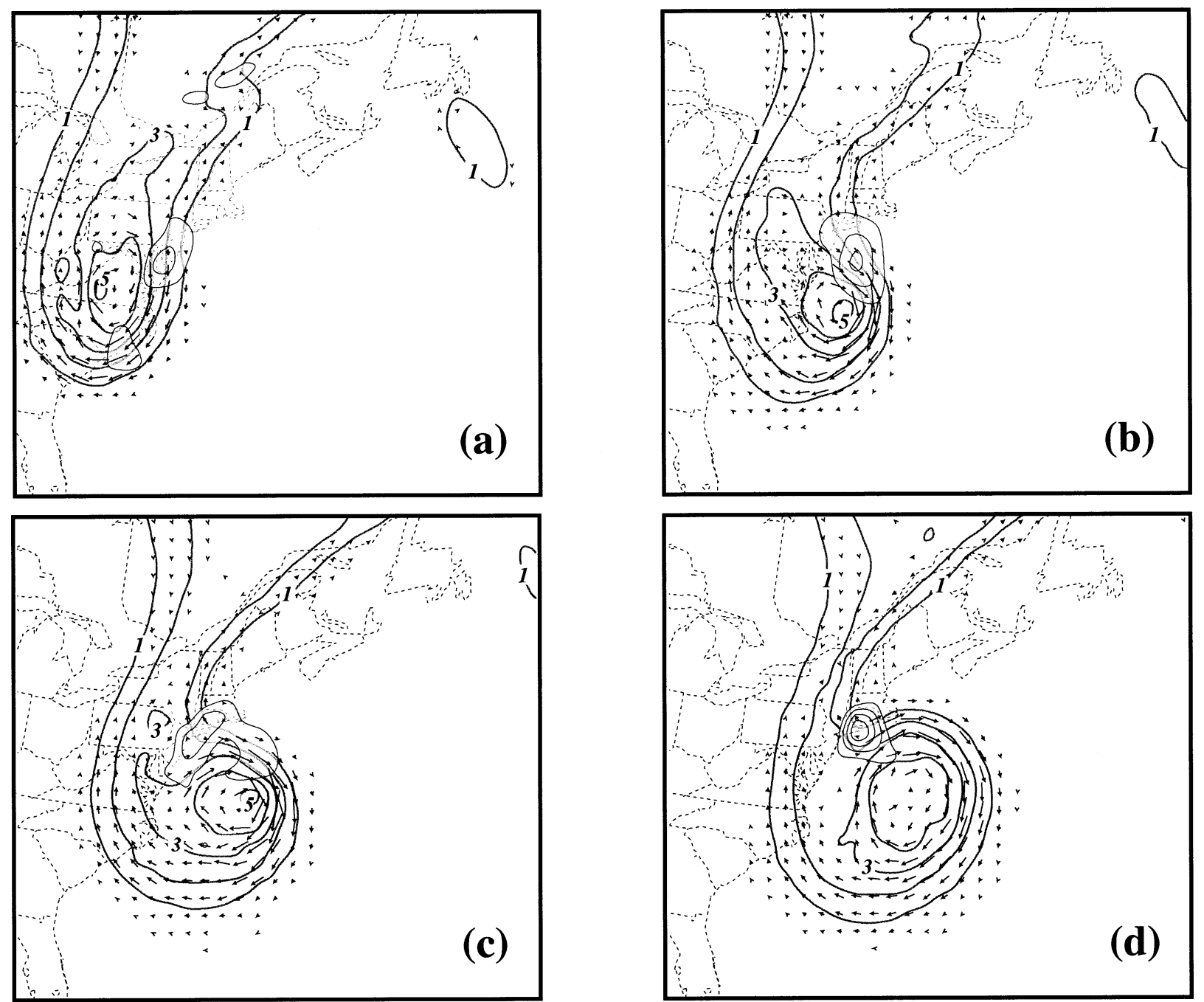

FIG. 15. Potential vorticity isertels and $\mathbf{Q}_{\mathrm{PVs}}$ vectors in the $300-310-\mathrm{K}$ isentropic layer from the NLHR simulation at (a) 1800 UTC 31 Mar, (b) 0000 UTC 1 Apr, (c) 0600 UTC 1 Apr, and (d) 1200 UTC 1 Apr 1997. Solid lines are isertels (PVU); and are contoured every 1 PVU. Divergence of $\mathbf{Q}_{\mathrm{PVs}_{\mathrm{s}}}$ (light shading) are labeled in units of $10^{-22} \mathrm{~K} \mathrm{~kg}^{-1} \mathrm{~s}^{-3}$ and are contoured every $1 \times 10^{-22} \mathrm{~K} \mathrm{~kg}^{-1} \mathrm{~s}^{-3}$ starting at $1 \times 10^{-22} \mathrm{~K} \mathrm{~kg}^{-1} \mathrm{~s}^{-3}$. Divergence of $\mathbf{Q}_{\mathrm{PVs}}$ is consistent with a kinematic tendency to produce a PV trough (see text for explanation).

sphere. Thus, it is possible to examine the occlusion process, as defined above, by considering the manner by which the upper-tropospheric PV (or, equivalently, the tropopause $\theta$ ) acquires the treble clef morphology.

In this paper the role of latent heat release in the occlusion process of an intense winter cyclone was examined using output from companion full physics and no-latent-heat-release simulations of the event performed using the MM5. Comparison of the FP and NLHR simulations revealed that though the lower-tropospheric thermal structure was quite similar (both simulations possessed a well-developed lower-tropospheric occluded thermal ridge), the 3D structure of the occluded quadrant was quite different between the two simulations. The NLHR case was characterized by a shallow, ill-defined occluded thermal structure, whereas the FP simulation possessed the troposphere-deep trowal structure characteristic of warm occluded cyclones. Consistent with these differences in tropospheric thermal structure, the FP cyclone displayed a robust treble clef $\mathrm{PV} / \theta$ structure at the tropopause in its postmature phase, while a considerably less robust version characterized the NLHR simulation. Thus, the upper-tropospheric PV minimum ( $\theta$ maximum) manifest in the "notch" of the PV/ $\theta$ treble clef was considerably weaker in the NLHR simulation. We therefore considered two potential mechanisms by which LHR might accelerate and intensify the production of the notch in the $\mathrm{PV} / \theta$ treble clef.

First, with the aid of piecewise PV inversion, the kinematic role of the tropopause-level circulation associated with the diabatically generated tropospheric PV was explored. It was hypothesized that this circulation might significantly contribute to the development of the 
notch by producing a concentrated region of negative upper-tropospheric PV advection in that region. The tropopause-level $M_{\text {pert }}$ flow was found to be anticyclonic and centered east of the upper-tropospheric PV maximum. As a consequence, the $M_{\text {pert }}$ flow produced predominantly positive PV advection in the vicinity of the notch. Therefore, kinematic rearrangement of the tropopause PV by the $M_{\text {pert }}$ flow was not responsible for the development of the notch in this case, and consequently had little effect on the production of the warm occluded thermal structure.

The second approach employed calculations of the diabatic PV tendency and demonstrated that the initial development of the notch was a direct consequence of dilution of upper-tropospheric PV resulting from LHR in the occluded quadrant. As this dilution began to carve out the treble clef notch, the low-latitude PV feature became progressively more isolated from the higherlatitude reservoir. This cutting off process, in turn, isolated the tropopause-level cyclonic circulation associated with the low-latitude PV feature. As a consequence, the advection of low PV by the tropopause-level winds contributed to the rapid growth of the PV notch during the late stages of the life cycle. Although analysis of the along-isertel component of the diagnostic $\mathbf{Q}_{\mathrm{PV}}$ vector in the NLHR simulation demonstrated an adiabatic, kinematic tendency to produce an upper-tropospheric PV treble clef in this case, the resulting NLHR treble clef structure was much weaker and slower to develop than the structure present in the FP simulation. Taken as a whole, the results of the analyses presented here strongly suggest that latent heat release plays a primary role in the production of the characteristic occluded structures observed in nature. In order to fortify this contention, future work will focus on contrasting dry and moist idealized cyclone simulations performed using the idealized version of the University of Wisconsin-Nonhydrostatic Modeling System (UW-NMS).

Finally, prior investigation of the adiabatic, QG dynamics of the occluded quadrant has shown that an underlying dynamical forcing (convergence of $\mathbf{Q}_{s}$ ) simultaneously promotes development of the isobaric thermal ridge characteristic of the thermal structure of occluded cyclones and provides the predominant dynamical support for ascent within the occluded quadrant (Martin 1999a). In the absence of latent heat release, the forced ascent would tend to erode the isobaric thermal ridge through vertical advection of $\theta$ (i.e., adiabatic cooling). The results presented here represent an extension to this emerging dynamic/conceptual model by providing evidence that the occlusion process depends upon the interaction of a characteristic dynamical forcing and the latent heat release that results from the forced ascent. The cold and warm frontal structures that develop in midlatitude cyclones are produced by kinematic frontogenesis and are not greatly altered in their essential structural characteristics by the release of latent heat. The fact that the development of an occluded thermal structure appears to depend so intimately on latent heat release further highlights the fundamentally different nature of the occlusion process as compared to traditional frontogenesis. We therefore reiterate the suggestion of Martin (1999a) that further insight into the nature of the occlusion process will arise only when it is no longer viewed as a traditional frontal process.

Acknowledgments. This work was supported by the National Science Foundation under Grant ATM9813398. The comments of Prof. Gary Lackmann of North Carolina State University and two anonymous reviewers are appreciated.

\section{REFERENCES}

Bjerknes, J., and H. Solberg, 1922: Life cycle of cyclones and the polar front theory of atmospheric circulation. Geofys. Publ., 3, $1-18$

Cammas, J.-P., D. Keyser, G. M. Lackmann, and J. Molinari, 1994: Diabatic redistribution of potential vorticity accompanying the development of an outflow jet within a strong extratropical cyclone. Preprints, Int. Symp. on the Life Cycles of Extratropical Cyclones, Vol. II, Bergen, Norway, Geophysical Institute, University of Bergen, 403-409.

Charney, J., 1955: The use of the primitive and balance equations. Tellus, 7, 22-26.

Crocker, A. M., W. L. Godson, and C. M. Penner, 1947: Frontal contour charts. J. Meteor., 4, 95-99.

Davies, H. C., and A. M. Rossa, 1998: PV frontogenesis and uppertropospheric fronts. Mon. Wea. Rev., 126, 1528-1539.

- C. Schar, and H. Wernli, 1991: The palette of fronts and cyclones within a baroclinic wave development. J. Atmos. Sci., 48, 1666-1689.

Davis, C. A., and K. A. Emanuel, 1991: Potential vorticity diagnostics of cyclogenesis. Mon. Wea. Rev., 119, 1929-1953.

_ condensation in numerical simulations of extratropical cyclogenesis. Mon. Wea. Rev., 121, 2309-2330.

Dudhia, J., 1989: Numerical study of convection observed during the winter monsoon experiment using a mesoscale two-dimensional model. J. Atmos. Sci., 46, 3077-3107.

Emanuel, K. A., M. Fantini, and A. J. Thorpe, 1987: Baroclinic instability in an environment of small stability to slantwise moist convection. Part I: Two-dimensional models. J. Atmos. Sci., 44, 1559-1573.

Ertel, H., 1942: Ein Neuer hydrodynamischer Wirbelsatz. Meteor. Z., 59, 271-281.

Galloway, J. L., 1958: The three-front model: Its philosophy, nature, construction and use. Weather, 13, 3-10.

- 1960: The three-front model, the developing depression and the occluding process. Weather, 15, 293-309.

Godson, W. L., 1951: Synoptic properties of frontal surfaces. Quart. J. Roy. Meteor. Soc., 77, 633-653.

Golding, B., 1984: A study of the structure of mid-latitude depressions in a numerical model using trajectory techniques. I: Development of ideal baroclinic waves in dry and moist atmospheres. Quart. J. Roy. Meteor. Soc., 110, 847-879.

Grell, G. A., 1993: Prognostic evaluation of assumptions used by cumulus parameterizations. Mon. Wea. Rev., 121, 764-787.

— J. Judhia, and D. R. Stauffer, 1994: A description of the fifthgeneration Penn State/NCAR Mesoscale Model (MM5). NCAR Tech. Note NCAR/TN-398+STR, 117 pp.

Hong, S.-Y., and H.-L. Pan, 1996: Nonlocal boundary layer vertical diffusion in a medium-range forecast model. Mon. Wea. Rev., 124, 2322-2339.

Hoskins, B. J., M. E. McIntyre, and A. W. Robertson, 1985: On the 
use and significance of isentropic potential vorticity maps. Quart. J. Roy. Meteor. Soc., 111, 877-946.

Korner, S. O., and J. E. Martin, 2000: Piecewise frontogenesis from a potential vorticity perspective: Methodology and a case study. Mon. Wea. Rev., 128, 1266-1288.

Kuo, Y.-H., R. J. Reed, and S. Low-Nam, 1992: Thermal structure and airflow in a model simulation of an occluded marine cyclone. Mon. Wea. Rev., 120, 2280-2297.

Market, P. S., and D. Cissell, 2002: Formation of a sharp snow gradient in a midwestern heavy snow event. Wea. Forecasting, 17, 723-738.

Martin, J. E., 1998a: The structure and evolution of a continental winter cyclone. Part I: Frontal structure and the classical occlusion process. Mon. Wea. Rev., 126, 303-328.

— 1998b: The structure and evolution of a continental winter cyclone. Part II: Frontal forcing of an extreme snow event. Mon. Wea. Rev., 126, 329-347.

_ 1999a: Quasigeostrophic forcing of ascent in the occluded sector of cyclones and the trowal airstream. Mon. Wea. Rev., 127, $70-88$.

_ 1999b: The separate roles of geostrophic vorticity and deformation in the midlatitude occlusion process. Mon. Wea. Rev 127, 2404-2418.

— , and N. Marsili, 2002: Surface cyclolysis in the North Pacific Ocean. Part II: Piecewise potential vorticity diagnosis of a rapid cyclolysis event. Mon. Wea. Rev., 130, 1264-1281.

Mass, C. F., and D. M. Schultz, 1993: The structure and evolution of a simulated midlatitude cyclone over land. Mon. Wea. Rev. 121, 889-917.

Mlawer, E. J., S. J. Taubman, P. D. Brown, and M. J. Iacono, 1997: Radiative transfer for inhomogeneous atmospheres: RRTM, a validated correlated-k model for the longwave. J. Geophys. Res. 102, $16663-16682$.

Morgan, M. C., and J. W. Nielsen-Gammon, 1998: Using tropopause maps to diagnose midlatitude weather systems. Mon. Wea. Rev., 126, 2555-2579.
Penner, C. M., 1955: A three-front model for synoptic analyses. Quart. J. Roy. Meteor. Soc., 81, 89-91.

Polavarapu, S. M., and W. R. Peltier, 1990: The structure and nonlinear evolution of synoptic scale cyclones: Life cycle simulations with a cloud-scale model. J. Atmos. Sci., 47, 2645-2672.

Pomroy, H. R., and A. J. Thorpe, 2000: The evolution and dynamical role of reduced upper-tropospheric potential vorticity in Intense Observing Period One of FASTEX. Mon. Wea. Rev., 128, 18171834.

Raymond, D. J., 1992: Nonlinear balance and potential vorticity thinking at large Rossby number. Quart. J. Roy. Meteor. Soc., 118, 987-1015.

Reed, R. J., Y.-H. Kuo, and S. Low-Nam, 1994: An adiabatic simulation of the ERICA IOP 4 storm: An example of quasi-ideal frontal cyclone development. Mon. Wea. Rev., 122, 2688-2708.

Reisner, J., R. Rasmussen, and R. T. Bruintjes, 1998: Explicit forecasting of supercooled liquid water in winter storms using the MM5 mesoscale model. Quart. J. Roy. Meteor. Soc., 124B, 1071-1107.

Rossby, C. G., 1940: Planetary flow patterns in the atmosphere. Quart. J. Roy. Meteor. Soc., 66, 68-87.

Schultz, D., and C. Mass, 1993: The occlusion process in a midlatitude cyclone over land. Mon. Wea. Rev., 121, 918-940.

— - D. Keyser, and L. F. Bosart, 1998: The effect of large-scale flow on low-level frontal structure and evolution in midlatitude cyclones. Mon. Wea. Rev., 126, 1767-1791.

Stoelinga, M., 1996: A potential vorticity-based study of the role of diabatic heating and friction in a numerically simulated baroclinic cyclone. Mon. Wea. Rev., 124, 849-874.

Takayabu, I., 1986: Roles of horizontal advection on the formation of surface fronts and on the occlusion of a cyclone developing in the baroclinic westerly jet. J. Meteor. Soc. Japan, 64, 329345 .

Thorncroft, C. D., B. J. Hoskins, and M. E. McIntyre, 1993: Two paradigms of baroclinic-wave life-cycle behaviour. Quart. J. Roy. Meteor. Soc., 119, 17-55. 